Journal of Financial Economics 00 (0000) 000-000

\title{
Underinvestment vs. overinvestment: evidence from price reactions to pension contributions
}

\author{
Francesco Franzoni $^{\mathrm{a}^{*}}$ \\ ${ }^{a}$ Swiss Finance Institute at the University of Lugano, 6904, Switzerland
}

Received 5 September 2007; revised 20 May 2008; accepted 20 June 2008

\begin{abstract}
Mandatory contributions to defined benefit pension plans provide a unique identification strategy to estimate the market's assessment of the value of internal. resources controlling for investment opportunities. The price decrease following a pension-induced drop in cash is magnified for firms that appear a priori more financially constrained, suggesting a negative effect of financing frictions on investment. In contrast, low control on managerial discretion attenuates the negative price reaction to contributions consistent with empire-building theories. While overinvestment seems to be the prevalent distortion in a panel of large firms, underinvestment appears to dominate in a sample that is more representative of the cross-section of listed companies.
\end{abstract}

Keywords: financial constraints, corporate governance, underinvestment, overinvestment JEL Classifications: G32, G34

I thank seminar participants at HEC, Paris, University of Lausanne, University of Lugano, and Tilburg University. The paper benefited from discussions with Giovanni Barone-Adesi, Laurent Calvet, Jonathan Lewellen, Sebastien Michenaud, Joshua Rauh, Jeremy Stein, David Thesmar, Toni Whited, and David Zion. I am especially grateful to François Degeorge and an anonymous referee for important contributions.

*Corresponding author contact information: Swiss Finance Institute - University

of Lugano, Via Buffi 13, Lugano, 6904, Switzerland. Tel.: +41 58-666-4117. Fax: +41 58-666-4734.

E-mail address: francesco.franzoni@unisi.ch

0000-000X/00/ \$ see front matter @ 0 0000Published by Elsevier Science B.V. All rights reserved 


\section{Introduction}

In interpreting the empirical literature on corporate investment, Stein (2003) argues that while it is hardly questionable that financial slack matters for investment, it is less clear to what extent this relationship is due to financing constraints or to empire-building. On the one hand, by raising the costs of external funds, financial frictions may cause a sub-optimal level of investment 1 This makes investment sensitive to the availability of cheap internal funds. On the other hand, if managers have empire-building preferences, they will use free cash flows to fund investment projects beyond the level that maximizes shareholders' value (Jensen, 1986). Like costly external finance, this argument also leads to the prediction that investment is increasing in internal resources. Although the two theories are observationally equivalent with respect to the sensitivity of investment to cash flows, their policy implications are obviously different. Furthermore, the two hypotheses may very well coexist in a unified model that admits both under- and overinvestment. Then, the more interesting question is which distortion prevails empirically.

The goal of this paper is to shed light on this issue. More specifically, the paper develops an identification strategy for the impact of costly external finance and empire-building on firm value. First, the objective is to test whether there is a significant effect on market value of the implications of these theories. Then, the analysis attempts a comparison of the importance of the two distortions.

A simple consideration inspires the methodology of this paper. One obvious dimension along which the empirical predictions of the costly-external-finance and empire-building theories differ is the value that the market attributes to a firm's cash flows. Converting cash into a less liquid asset is neutral for equity in a frictionless world. However, this action negatively impacts shareholders' value in a firm that faces costly external finance. For a constrained company, the shadow price of cash accounts for the higher cost of external funds and the net present value (NPV) of the investment projects that are forgone because of the loss of liquidity. On the other hand, the same

\footnotetext{
${ }^{1}$ The theoretical literature motivates the existence of financial constraints on the grounds of both asymmetric information (Myers and Majluf, 1984; Greenwald, Stiglitz, and Weiss, 1984) and moral hazard (Jensen and Meckling, 1976; Grossman and Hart, 1982; Stulz, 1990 Hart and Moore, 1995).
} 
shift in internal resources is less costly for the investors of firms in which managers pursue their own interest. In these companies, one needs to adjust the face value of internal resources by the negative NPV of the wasteful projects that empire-building managers would undertake.

To test this intuition the paper builds on the results from two previous studies. Most important, Rauh's (2006) work shows that investment decreases when firms make cash contributions to their defined benefit pension plans. The law mandates a company to transfer cash to its underfunded plans (that is, plans in which the present value of the future pension obligations exceeds the assets set aside to pay for these pensions). With the appropriate controls, mandatory pension contributions represent an exogenous shift in internal resources, which allows the researcher to get around the unobservability of the investment opportunity set. Franzoni and Marin's (2006a) paper provides the other set of relevant results. These authors significantly predict negative stock returns in the years that follow the emergence of a large pension deficit. Given that the companies sponsoring severely underfunded plans are likely to incur mandatory pension contributions in the near future, the authors suggest that their results partly hinge on the market being surprised by these cash transfers to the pension plan.

Based on these results, the approach of this paper is to test whether the abnormal returns that are associated with mandatory contributions differ along the two dimensions of financial constraints and exposure to empire-building. The underlying assumption is that the change in firm value reflects the investment effect shown by Rauh. In this light, the evidence that price reactions are positively correlated with a priori measures of financial constraints is interpreted as a sign that the cash decrease pushes these firms below their optimal level of investment (underinvestment). By contrast, finding an inverse correlation between the price reaction to contributions and likely predictors of empire-building suggests that managers are using free cash flows to pursue negative NPV projects (overinvestment). Acknowledging that incentives for under- and overinvestment may coexist even within the same firm, one can look at the distribution of price reactions across firms to find which distortion is considered more important by the market.

It is worth stressing that the use of mandatory pension contributions has the advantage of solving a serious identification problem. Following the cash flow drop, one should expect heterogeneity in 
price reactions across firms as a function of the different investment opportunities that they face. Specifically, in firms with poor investment prospects the value of cash flows is naturally lower. This fact introduces a bias if the likelihood of paying contributions is correlated with investment opportunities. A further difficulty emerges if investment opportunities correlate with the chosen measures of financial constraints and empire-building opportunities. This paper adopts Rauh's identification strategy, which exploits the non-linear relation between mandatory contributions and the plan funding status? This identification strategy distinguishes my work from previous studies that look at price reactions after the announcement of investment decisions, but do not deal with the problem of omitted investment opportunities.

The exact date on which contributions are paid is not known. Hence, a proper event study of price reactions in the days surrounding the announcement of contributions is not feasible. Yet, a number of arguments suggest that one can still make fruitful use of the contributions data, as the price impact is likely spread over a long horizon. In particular, the results in Coronado and Sharpe (2003) and Franzoni and Marin (2006a) reveal that the market is slow in impounding pension information into value. This fact is possibly caused by a lack of clarity in pension accounting and/or by managers' practice of using pension items to manipulate earnings, as reported by Bergstresser, Desai, and Rauh (2006). This evidence supports the choice of measuring the value implications of contributions over a one-year horizon. The starting date for computing returns is July of the year following the payment of contributions. July represents the final deadline for filing Form 5500 with the IRS (Annual Report of Employee Benefit Plan), from which the data on mandatory contributions are drawn. Further reassurance on the validity of the research design comes from the consideration that, as long as the speed of information impounding does not correlate with the financial constraints or empire-building characteristics of the firm, the choice of the return measurement window does not interfere with the qualitative conclusions of the analysis.

To capture financial constraints, I rank firms according to three standard measures: the Whited and $\mathrm{Wu}$ (2006) index, the Cleary (1999) index, and the Kaplan and Zingales (1997) index. The

\footnotetext{
${ }^{2}$ The funding status is the difference between assets and liabilities in the pension plan, where the liabilities are the present value of future pension obligations.
} 
evidence suggests an economically important role for financial constraints. Specifically, a drop in cash is more costly in constrained firms, irrespective of the chosen measure of financial frictions. The magnitudes suggest a large impact of financing constraints on valuation, as one dollar in contributions reduces value by about $\$ 1.30$ for constrained firms. In a frictionless world, one should expect zero impact, as contributions are a value neutral transfer to a fully owned subsidiary of the firm. The qualitative results are robust to alternative definitions of abnormal returns and controls for concurring explanations.

To capture exposure to empire-building, I refer to studies that identify an effect of corporate governance on performance. In this context, Gompers, Ishii, and Metrick (2003), and Bebchuck, Cohen, and Ferrell (2004) develop some indices that are meant to measure the extent to which external governance mechanisms mitigate the agency conflicts between managers and shareholders. In particular, they focus on the anti-takeover provisions (ATP) that shield managers from the disciplinary role of the market for corporate control. Also, following Cremers and Nair (2005) and Dittmar and Mahrt-Smith (2007), I use the amount of blockholdings by institutional investors as a measure of the quality of internal governance. The results suggest that the market anticipates that empire-building is an important determinant of investment for some firms. Specifically, a shift of cash towards the pension plan in a firm with worse corporate governance is given significantly less weight by the market. The evidence of overinvestment in this paper is considerably stronger than what is found in previous studies (see, e.g., Faulkender and Wang, 2006; Dittmar and Mahrt-Smith, 2007). Arguably, the total change in the stock of cash, which is examined in the previous literature, is less likely to be entirely wasted in negative NPV projects or to be entirely subtracted from valueenhancing investments than the marginal changes in cash flow due to pension contributions, which are the present focus.

The next step is the comparison of the importance of under- and overinvestment. For the sample of firms for which the governance index is available, I study the distribution of price reactions conditional on the extent of financial constraints and governance quality. In this set of large firms, the exercise suggests that the market anticipates a slightly predominant role for overinvestment. For the whole sample, the data availability limits the analysis to the unconditional price reaction. 
Nevertheless, the estimates are sufficiently negative and significant to allow conclusive inference. For this panel of firms, which more closely resemble the universe of listed companies, the evidence suggests that underinvestment is the more important distortion.

The interpretation of the results in this paper hinges on the assumption that the chosen indices of financial constraints and governance actually capture heterogeneity in the exposure to under- and overinvestment. To corroborate the validity of this hypothesis, the final step of the paper is to look at some descriptive evidence on the firms that, based on the aggregate price reaction, rank differently in the spectrum from under- to overinvestment. The data suggest that the companies that are predicted to overinvest are larger, older, have more coverage by analysts and rating agencies, and are characterized by lower institutional ownership. The fact that these statistics correspond to the theoretical prior on the identity of firms that under/overinvest is reassuring about the empirical soundness of the proposed interpretation.

The paper is organized as follows. Section 2 draws the connection of the paper to other studies. Section 3 describes the variables that are used in the analysis. Section 4 details the empirical strategy. Section 5 applies the empirical strategy to identify heterogeneity in price reactions to mandatory contributions across the financial constraints status and the corporate governance dimension. Section [6 uses price reactions to contributions to rank firms on the spectrum from underto overinvestment in order to assess the relative importance of the two distortions. The same section contains descriptive statistics on the firms in this ranking. Section 7 provides some robustness checks. Finally, Section 8 draws the conclusions of this work.

\section{Related literature}

The literature on financial constraints is abundant. Following Fazzari, Hubbard, and Petersen (1988), a strand of literature has adopted reduced-form regressions of investment on cash flow, using average Tobin's $q$ to control for investment opportunities. An alternative approach, which circumvents the use of $q$, relies on natural experiments to identify exogenous variation in internal 


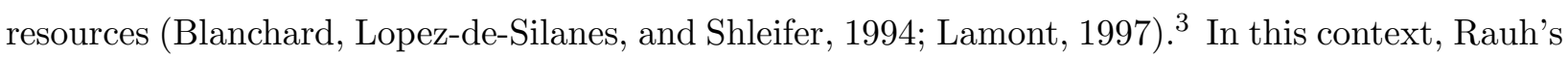
(2006) study represents the first natural experiment in a large sample setting. This paper is closely related to Rauh (2006), as it adopts the same identification device. Moreover, the finding that price reactions triggered by pension contributions are larger for constrained firms can be interpreted as the projection in the space of asset prices of the real effect identified in Rauh's paper.

The contribution of this work to the financing constraints literature is the focus on price reactions. The empirical studies on financial frictions have focused on a wide range of investments that, besides expenditure on plant and equipment, include $R \& D$, inventories, pricing for market share, and labor hoarding during recessions $[$ The advantage of the methodology in this paper is that it provides a comprehensive measure of the costs of external finance and the value of forgone investment that includes quantities that are not otherwise measurable (i.e., human capital and other intangibles). In this sense, while it is a reduced-form approach, it achieves a comparable result to the structural models of investment (Hennessy and Whited, 2007).

I find that Gompers, Ishii, and Metrick's (2003) index helps to identify firms whose cash flows are valued less by the market. This evidence supports these authors' conclusions that ATPs affect value through the empire-building channel. In this context, other related papers are Bebchuck, Cohen, and Ferrell (2004), Bebchuck and Cohen (2005), and Cremers and Nair (2005).

As in this paper, a number of previous studies look at price reactions after corporate events across measures of the quality of governance and find evidence in favor of Jensen's (1986) free-cash flow hypothesis. These works focus on returns after the announcement of capital expenditures (McConnell and Muscarella, 1985), acquisitions (Lewellen, Loderer, and Rosenfeld, 1985; Morck, Shleifer, and Vishny, 1990; Lang, Stulz, and Walkling, 1991; Masulis, Wang, and Xie, 2007), and dividend initiations (Pinkowitz, Stulz, and Williamson, 2006; Officer, 2007). The fundamental difference in the present approach relative to previous work is the fact that the research design allows to control for the omitted investment opportunity set, which is an obvious determinant of

\footnotetext{
${ }^{3}$ Erickson and Whited (2000) and Gomes (2001) point out the potential failures of average $q$ to control for investment opportunities due to measurement error.

${ }^{4}$ See Hubbard (1998) and Stein (2003) for references.
} 
post-event price reactions and is potentially correlated with the chosen measure of empire-building $\underline{5}$

Closely related to this paper, some studies focus on the marginal value of cash and find evidence of financial constraints (Pinkowitz and Williamson, 2004; Faulkender and Wang, 2006; Denis and Sibilkov, 2007) and corporate governance effects (Dittmar and Mahrt-Smith, 2007; Frésard and Salva, 2007). Relative to this literature, the incremental contribution of my paper is to identify a cash flow component (mandatory contributions) that is clearly orthogonal to the investment opportunity set, once one controls for the pension plan funding status.

Overall, the main contribution of the paper is to provide a unified empirical framework to separate the implications of under- and overinvestment theories. With respect to this goal, the paper to which the present work is closest in spirit is the one by Blanchard, Lopez-de-Silanes, and Shleifer (1994). They look at the investment behavior of a small sample of firms that receive cash windfalls. Instead, my large sample approach focuses on the market's valuation of the cash flows of companies that are mandated to pay pension contributions. [0]

\section{Data and variable construction}

\subsection{Pension items, financial constraints, and governance}

Mandatory contributions to defined benefit pension plans are constructed by Rauh (2006) from Form 5500 filings $!^{7}$ These data are only available for fiscal years from 1990 through 1998 . A necessary but not sufficient condition for a firm to incur mandatory contributions is that one of its pension plans be underfunded. The formula to compute mandatory contributions is fairly complex and changes over the period of interest. Broadly speaking, contributions depend on the funding history and the pension cost for the current year on a plan-by-plan basis $\stackrel{8}{[}$ Rauh's data contain

\footnotetext{
${ }^{5} \mathrm{~A}$ notable exception that also deals with the endogeneity problem is the paper by Officer (2007), who uses a change in the tax rate for dividends as a natural experiment to study the market response to dividend initiations.

${ }^{6}$ In the same vein, the large sample study by Chaney, Sraer, and Thesmar (2007) finds results that are consistent with the evidence in this paper. Using variation in real estate prices as an exogenous measure of changes in collateral value, they show that investment is affected by net worth. However, the relaxation of financial constraints is good news only for firms with strong shareholder protection, as measured by Gompers, Ishii, and Metrick's (2003) index.

${ }^{7}$ I am grateful to Joshua Rauh for making his data available.

8 Specifically, contributions depend on the funding status of the domestic Defined Benefit (DB) plans, on a plan-by-plan basis. The plan funding status results from comparing the plan liabilities (present value of future benefits to which the workers are entitled) with the plan assets (the market value of the assets that have been set
} 
mandatory contributions at the firm level. As reported by the author, approximately one-quarter of Compustat firms had defined benefit pension plans in the 1990s, but these firms account for more than half of Compustat firms' book value. Out of these observations, one selects only those that have valid Form 5500 information. The final data set provided by the author contains 8,030 firmyear observations on 1,522 firms. Also available in Rauh's data is the aggregate funding status of all defined benefit plans sponsored by a firm. It is computed by subtracting the aggregate pension liabilities from the aggregate pension assets at the firm level.

I match contributions by firm and fiscal year to the accounting information from Compustat. To avoid the potential sample selection bias induced by Compustat's practice of backfilling the data, a firm needs to have available accounting data for at least two years prior to appearing in the sample.

The analysis uses three indices of financial constraints. The Appendix provides the details on their construction along with other variable definitions. The first index is the one conceived by Whited and Wu (2006), which I label WW index. These authors fit the shadow value of external funds from a structural model of investment onto a number of observable variables. The second measure of financial constraints is the Cleary (1999) index in the version by Hennessy and Whited (2007). Cleary uses discriminant analysis based on observable company characteristics to construct a $Z$-score for the firm's likelihood of increasing or decreasing dividend payments. Thirdly, I use the Kaplan and Zingales index (KZ index), as developed by Lamont, Polk, and Saa-Requejo (2001). This score is obtained by running an ordered logit of Kaplan and Zingales' (1997) scale of financing constraints onto observable characteristics. Although the estimation is originally performed on a sample of 49 firms, the literature has extensively applied this measure to classify firms in large samples. In synthesis, the KZ index identifies as constrained those firms with low cash stock, low

aside to provide for the pensions). The plans that are more than fully funded do not incur mandatory contributions. For the plans where assets are below liabilities, the required pension contribution is the maximum of two components: the minimum funding contribution (MFC) and the deficit reduction contribution (DRC). The DRC as a percentage of firm funding is given by $\min \{0.30,[0.30-0.25 *$ (funding status -0.35 ) $]\}$ for 1987 to 1994 and $\min \{0.30,[0.30-0.40 *$ (funding status -0.60$)]\}$ for 1995 and later. The MFC is defined as the "normal cost" plus $10 \%$ of underfunding. The "normal cost" roughly corresponds to the present value of pension benefits accrued during the year. Other details are given in Rauh (2006). 
cash flow, and high leverage. Firms ranking high with the WW index are small, rely heavily on equity financing, have low cash flow, and are slow-growing firms in fast-growing industries. Firms appearing constrained by the Cleary index are slow-growing, have low profit margins, and have few resources to cover their debt burdens. The indices are defined so that higher levels denote firms that are a priori more financially constrained. To be included in the sample a firm needs to have sufficient data to construct the three measures.

The purpose of adopting three indices is to provide evidence that is robust to alternative measures of financial frictions. Hennessy and Whited (2007) distinguish two dimensions of financial constraints. The first dimension is the firm's need for external funds, as measured by the ratio of first-best investment to internal resources. The second dimension is the cost of external funds, which is the additional cost the firm would incur if it used external rather than internal finance. According to these authors, the three indices capture the need for external funds. However, the results in the paper are also robust to other classification schemes based on size and dividend payments, which according to Hennessy and Whited (2007) are better proxies for the cost of external funds $\stackrel{9}{9}$

To capture exposure to empire-building, the primary variable is Gompers, Ishii, and Metrick's (2003) corporate governance index (G) $!^{10}$ They use data from the Investor Responsibility Research Center (IRRC) providing 24 distinct corporate governance provisions on about 1,500 firms since 1990. This score is meant to capture the balance of power between managers and shareholders in a corporation. The index adds one for each ATP adopted by the firm. Hence, higher levels of the index imply less shareholder protection. To avoid reducing the sample size excessively, I use the availability of the $\mathrm{G}$ index as a selection criterion only for the parts of the paper that focus on price reactions across levels of the governance index. I also present results that use Bebchuck, Cohen, and Ferrell's (2004) entrenchment index (BCF), which is based on six out of the original 24 provisions 11 Finally, unlike the two other indices that measure external governance

\footnotetext{
${ }^{9}$ These results are not reported, but are available upon request.

${ }^{10}$ The index is available on Professor Metrick's Web site.

${ }^{11}$ These are four constitutional provisions that prevent a majority of shareholders from having their way (staggered boards, limits to shareholder bylaw amendments, supermajority requirements for mergers, and supermajority require-
} 
mechanisms, the third index focuses on the presence of large shareholders (Block), which operate as an internal monitoring device (see e.g. Shleifer and Vishny, 1986). As in Cremers and Nair (2005), this index measures the percentage share of ownership by institutional blockholders, defined to be an institutional shareholder with equity ownership greater than 5\%. Hence, higher values of the index denote potentially lower exposure to empire-building. The index is based on data from Securities and Exchange Commission (SEC) 13F filings (reports filed by institutional investment managers) reported by CDA/Spectrum!12

\subsection{Return measurement window}

The dependent variable in this study is stock returns over a period following the payment of pension contributions. As anticipated, the actual date on which contributions are paid is not available. This fact imposes a thorough consideration of the window over which the value impact of contributions is measured.

There are two main sources from which investors could learn about the contributions that are paid in year $t$. The publication dates of each source represent a likely candidate for the beginning of the return measurement window. First, the amount of total pension contributions is reported in the annual financial statements. The footnotes to the $10-\mathrm{K}$ contain a reconciliation of beginningof-year to end-of-year pension assets. Among the items that matter for this computation, the company reports the contributions it made in the fiscal year. Given that for most companies the fiscal year ends in December and the $10-\mathrm{K}$ is filed about three months later, it could make sense to start measuring returns in March of year $t+1$ 13 Second, a detailed description of the pension contributions for a given fiscal year is contained in Form 5500, which is filed annually with the IRS. These forms contain crucial information regarding the U.S. pension plans of the company. For example, the firm restates assets and liabilities of each plan in a way that is relevant for funding purposes and that is different from the format used in the accounting statements. Most important, these forms contain the breakdown of contributions into the amount that the company voluntarily

ments for charter amendments), and two readiness provisions that boards put in place to prevent hostile takeovers (poison pills and golden parachutes).

${ }^{12}$ I am grateful to Martijn Cremers for providing the index.

${ }^{13}$ The pension information is not available in the quarterly statements. 
chooses to pay and the amount that is paid to meet regulatory requirements (i.e., mandatory contributions). While the exact date when Forms 5500 are filed is not provided in the data set, the deadline for filing is seven months after the fiscal year end. Hence, by July of year $t+1$ the amount of mandatory contributions has become public information.

For completeness, one has to mention the fact that on a few occasions firms disclose the contributions at the time they make them in the course of year $t$. These announcements, however, are not likely to matter for this study for a number of reasons. First, they are very sporadic. Secondly, they only provide the amount of contributions that are paid up to some point in the fiscal year, not the total amount for the year. Last, the announcements are made on a voluntary basis. As such, they are sending a signal to the market that differs from the information provided by mandatory contributions. I will argue more on this point below, when I discuss the different informational content of the 10-K and Form 5500 .

Concerning the length of the window over which one should measure abnormal returns, a relevant indication comes from the results in Franzoni and Marin (2006a b), who show that the return reaction to pension information is long lasting. The authors argue that abnormal return reactions to pension plan underfunding can be predicted for at least five years after portfolio formation, suggesting that the market is slow in impounding this information into prices. Hence, I choose to measure abnormal returns over a one-year window as a compromise between the needs of capturing investors' slow reaction to the information and having non-overlapping observations on returns. The latter element improves the small sample behavior of the standard errors.

Given the previous discussion, annual abnormal returns should include at least one of the likely dates at which the market starts learning about contributions, that is, either March or July of year $t+1$. In the preliminary analysis for this work, I have used each a priori motivated date as the beginning of the return measurement window. While the qualitative implications are preserved in either case, the most significant evidence results from measuring returns from the beginning of July of year $t+1$. Then, I report only the estimates that are computed in this window.

To obtain further insight on the timing of information impounding, one can graphically inspect the evolution of stock prices for firms that pay contributions. I compute the cumulative abnormal 
returns (CAR) starting in January of year $t+1$ up to December of year $t+2$ for firms in different deciles of year- $t$ contributions. For the purpose of this exercise, contributions are normalized by total assets at the beginning of the year. Abnormal returns are defined as the difference between the monthly stock return and the return on a size-book-to-market-momentum matching portfolio (other return adjustments provide similar results). Given the purely descriptive purpose of this exercise, I omit the study of the statistical significance of the returns, for which the regression analysis is better suited. Fig. 1 reports the average CAR for the firms in the tenth decile of the distribution of mandatory contributions conditioning on the observations with positive contributions. Across the sample years, there are 184 firm-year observations in this decile. For comparison, I also plot the CAR for firms with zero contributions (4,427 observations). The graph shows that most of the differential impact of contributions on returns occurs after the first half of year $t+1$. This evidence corroborates the impression that the July-window captures a larger chunk of the reaction to the cash flow shock.

One can push the graphical analysis further and group stocks along the financial constraints (FC) dimension. Focusing only on the observations in the tenth decile of contributions for each year, I consider the companies in the top (constrained) and bottom (unconstrained) quartiles of the FC indices. Fig. 2 is constructed using the WW index as a measure of financial constraints (the other two indices yield similar conclusions). The figure anticipates one of the main results in the regression analysis. The negative returns associated with mandatory contributions are concentrated in the group of financially constrained firms. As in Fig. 1, most of the negative price reaction occurs after the first half of year $t+1$.

To complete the picture, I break down the analysis along the governance dimension. Fig. 3 plots CARs for the top group of contribution-paying firms that are either in the top (poorly governed) or bottom third (well governed) of the distribution of the governance index $(\mathrm{G})$. The price reaction to contributions displays a positive trend for poorly governed firms. While the regression analysis will establish that these positive abnormal returns are not significantly different from zero, it will also point out that the difference in price reactions between poorly and well-governed firms is positive and significant. This evidence suggests that the value of cash in poorly governed companies is 
discounted, which is possibly due to the anticipated negative NPV of empire-building projects. For the present purposes, the figure confirms the impression of delayed price reaction.

One may wonder what determined this delay in the reaction to contributions relative to the publication date of the 10-K. Realistically, a number of complementary factors could play a role.

First, the footnotes of the 10-K, as well as interim announcements of contribution payments, report the sum of voluntary and mandatory contributions. As argued, the breakdown into the two components is only available in Form 5500. This information is relevant to investors, because the implications of each component may differ. In particular, voluntary contributions might signal a healthy financial condition that allows the firm to run a well-funded pension plan and extract the positive returns from its assets. One would not expect a negative price reaction to this signal. In fact, there is anecdotal evidence suggesting that the market on a few occasions interpreted the announcement of cash contributions as good news! $\frac{14}{14}$ On the other hand, mandatory contributions are typically triggered by negative shocks to the pension plan that are likely to jeopardize the liquidity of the company. Fortunately, the econometric approach allows one to control for the differing implications of contributions in terms of investment opportunities. Still, this argument suggests that rational investors should care about the informational content of Form 5500 and base their inference on it.

Second, unlike the years 2002-2003, the pension issue was not in the spotlight during the time period covered by this study. Indeed, because of their good funding status, many companies were enjoying 'contribution holidays' 15 So, it is unlikely that analysts and investors paid much attention to the amount of contributions in the footnotes. As a consequence, the news about contributions must have traveled slowly in the market. This interpretation is consistent with the empirical

\footnotetext{
${ }^{14}$ The financial press reports situations in which stock prices reacted positively to the firm's announcement of current or future contributions as they signaled financial strength or the end of a pension problem. See the following examples: IBM in January 2003 (http://www.marketwatch.com/news/story/ibm-up-after-completing-pension/ story . aspx?guid=\%7B8414D43D\%2D522F\%2D4FAB\%2D97C5\%2D8A7DB3333AC0\%7D); GM in December 2003 (http://www . marketwatch. com/news/story/gm-add-41-bln-pension/story . aspx?guid=\%7B1B0EE3E7\%2D454B\% 2D413B\%2D95EA\%2D43891D763666\%7D).

${ }^{15}$ Contribution holidays are fiscal years in which the firm does not need to pay contributions because the pension plan is sufficiently funded. These situations were common in the late 1990s when the booming stock market increased the value of pension plan assets.
} 
evidence suggesting that bad news, in general, takes longer to spread among investors (Hong, Lim, and Stein, 2000).

Third, by increasing the asset base in the pension plan, contributions in a given year increase earnings per share (EPS) in that year. The effect works through the assumed return on plan assets, which reduces the net pension cost. Hence, given the market's focus on bottom line earnings (see, e.g., Chan, Chan, Jegadeesh, and Lakonishok, 2006, and the survey evidence in Graham, Harvey, and Rajgopal, 2005), it is possible that the reaction to the $10-\mathrm{K}$ for contribution-paying firms was initially positive. Incidentally, this argument would help to explain the positive CAR in the first months of year $t+1$ in Fig. 1 .

Fourth, one can further justify the lack of prompt price reaction at the date of publication of the $10-\mathrm{K}$ on the grounds that the pension information, especially during the sample period, was not clearly displayed to investors. There is substantial evidence that the pension items were used by managers to manipulate earnings (Bergstresser, Desai, and Rauh, 2006) and that investors were misinterpreting this information (Coronado and Sharpe, 2003; Franzoni and Marin, 2006a). Furthermore, the revision of pension accounting in SFAS 132 (Statement of Financial Accounting Standards, Employers' Disclosures About Pensions and other Postretirement Benefits), which makes these items more transparent, came into effect in a later period than the one covered in this study.

Last, if investors did not learn about contributions from the year- $t$ 10-K, it has to be the case that later developments in year $t+1$ revealed their existence. Rauh (2006) shows that year-t contributions imply lower investment in the same year. This fall in investment likely shows up as reduced earnings growth in later years. Possibly, firms that needed to justify lower-than-expected EPS growth in year $t+1$ had to clearly point out the amount of prior-year contributions and their impact on investment. Consistent with this conjecture, Fig. 1 reveals that much of the negative price reaction took place around fiscal year ends (December), when more information about annual performance normally becomes available.

To conclude the discussion about the timing of information impounding, one can make the point that the ambiguity in the beginning of the event window is not likely to interfere with the conclusions of this paper. The same argument refers to the fact that ending the return measurement 
window in June of year $t+2$ is likely to miss part of the price reaction to contributions, as suggested by the persistent downward trend for the CAR in Fig. 1. Specifically, the focus of the analysis is the differential impact on value resulting from heterogeneity in the exposure to financial constraints and empire-building. To the extent that these characteristics do not correlate with the bias in measuring the return reactions, the incremental effects of financial frictions and governance that are identified in my paper remain valid. Reassuringly enough, some of the robustness checks in Section 7 suggest that these two dimensions do not correlate with cross-sectional proxies for the speed of information diffusion.

\subsection{Summary statistics}

As a consequence of the above discussion, I match contributions and accounting variables for fiscal years ending in year $t$ with annual returns between July of year $t+1$ and June of year $t+2$. To allow the interpretation of the regression slopes on contributions in terms of dollar effects, the dollar amount of contributions for year $t$ is divided by the firm's market capitalization at the end of June of year $t+1$. This causes the dependent variable (annual returns) and the independent variable (mandatory contributions over equity, $M C$ ) to have the same denominator. The same normalization is applied to the variable describing the firm's funding status $(F S)$. The financial constraints indices for year $t$ are matched with annual returns starting in year $t+1$. As for the governance indices, the information from the latest publication of the Investor Responsibility Research Center as of year $t+1$ is matched with annual returns in the same year. Annual returns are computed by compounding monthly returns from the Center for Research in Security Prices (CRSP) data set. In the end, sample returns range between July of 1991 and June of 2001! 16

The entire sample consists of 6,236 firm-year observations on 1,260 firms. When imposing the availability of $\mathrm{G}$ the sample is restricted to 4,157 observations on 827 firms. Table 1 reports summary statistics on the main variables in the analysis for the whole sample and the sample where

\footnotetext{
${ }^{16}$ Compustat reports a fiscal year as ending in the previous calendar year if the fiscal-year-end month is before June. When matching contributions and accounting information to market information from CRSP, I undo this transformation and use the actual fiscal year end. Consequently, for a small number of firms the available information on contributions stretches to 1999 and returns range to June of 2001.
} 
$\mathrm{G}$ is available!17 The average contribution is $0.2 \%$ of total equity in the large sample, while it is only $0.1 \%$ in the restricted sample. This number includes the observations for which contributions are zero (about $71 \%$ ). Conditioning on non-zero observations, the average $M C$ is about $0.7 \%$ and $0.4 \%$ in the full and restricted samples, respectively (not shown in the table). The average size in the sample is about $\$ 2,336$ million, which is about twice the average size of listed firms over this period (around $\$ 1,153$ million, from CRSP), as the companies sponsoring DB pension plans tend to be large. In turn, the average firm for which $\mathrm{G}$ is available is about $41 \%$ larger than the average firm in the whole sample. Not surprisingly, conditioning on the availability of G, firms appear to be less financially constrained.

The correlation between $M C$ and the FC indices is positive. As suggested in the introduction, this evidence corroborates the need to control for unobservable investment opportunities. Except for the correlation between the KZ and Cleary indices (53\%), the correlations among the financial constraints indices tend to be low, suggesting that the three classification schemes provide independent information. The WW index is strongly negatively correlated with size $(-63 \%)$, likely because it depends on total assets with a minus sign. Finally, the Block index is practically uncorrelated with the two other governance measures.

One question that arises is whether the firms that incur mandatory contributions are different from the rest of the sample along some dimension. Specifically, they could qualify as distressed companies. If that was the case, the empirical results that follow could not be generalized to the universe of listed firms and the interpretation of the price reactions would take a different connotation, specifically in terms of costs of financial distress.

Table 2 reports descriptive statistics on a number of characteristics for firms that pay and do not pay contributions. Also, among the firms with positive $M C$, I consider those with contributions above and below the conditional median of $M C$ (about $0.12 \%$ ). Consistent with the evidence on correlations, it appears that top-contribution firms rank as most constrained according to the

\footnotetext{
${ }^{17}$ Although the samples for which $\mathrm{BCF}$ and Block are available do not coincide with the sample where $\mathrm{G}$ is available, there is large overlap among the three samples. Hence, to save space, I only report summary statistics for the observations for which $\mathrm{G}$ is non-missing.
} 
three FC indices. Instead, there is no apparent difference in the $\mathrm{G}$ index across $M C$ groups. The relationship between $M C$ and firm size is hump-shaped, with the smallest firms in the top $M C$ group. A similar pattern describes firm age and the coverage by analysts and rating agencies. The relationship between $M C$ and book-to-market (BM) is instead U-shaped, with the top $M C$ firms displaying the highest BM. High $M C$ firms have the lowest cash flows, highest leverage, and are the least inclined to pay dividends, but the difference with respect to the other groups is not substantial and does not suggest a condition of financial distress. Moreover, top $M C$ firms rank lowest in terms of real sales growth (SG), operating margin (IMARG), interest cover (COVER), and financial slack (SLACK), which could indicate a condition of relative financial weakness for these companies. In summary, the bottom group of contribution-payers appears far from financial distress, while top-payers are more likely candidates for distress. The last point raises the need to further address the issue of financial distress in the robustness checks.

\section{Empirical strategy}

\subsection{Theoretical considerations}

The analysis in the paper focuses on the projection onto stock prices of the sensitivity of investment to pension contributions identified by Rauh (2006). He shows that a dollar paid in pension contributions reduces investment by about $\$ 0.60$ to $\$ 0.70$. Ultimately, the goal of this paper is to disentangle financial constraints and empire-building as the reasons for this dependency of investment on financial slack.

In a world with frictionless investment, one should not expect an impact on the equity value of the sponsoring company from a given amount of pension contributions. The pension plan is effectively a fully owned subsidiary of the sponsoring company. By increasing the assets in the pension plan, the cash that is paid in contributions reduces the net pension liability of the firm. Hence, the net effect on equity is zero. Investors appear to be aware of this logic, as testified by the following quote from a 2003 Goldman Sachs research report:

... Pension contributions don't add to, or subtract from, equity value. Pension contributions are funded from either cash flow, from existing cash in the bank, from assets 
$[\ldots]$, or from the sale of new debt or equity [...]. As a result, while a pension contribution reduces the net liability, it also either reduces the cash flow for shareholders, transfers cash or assets owned by shareholders to the retirees, or increases another liability by an equal amount... (Gary Lapidus and Jason Cuttler, "GM is swapping $\$ 10$ BN of pension liability for $\$ 10 \mathrm{BN}$ of another (debt)," 6/23/2003)

However, in a world with frictions, pension contributions can affect shareholder value. Specifically, because of the unavailability of cash or the exhaustion of the capacity of raising new capital, the firm may be prevented from undertaking investment projects. Rauh's result suggests that this situation is relevant in practice. I label the impact on firm value of pension contributions "the investment effect." The sign of the investment effect depends on whether the firm is below or above its frictionless level of investment $\frac{18}{18}$

On the one hand, one should expect a drop in shareholder value if the firm is underinvesting. One component of this decrease is the positive NPV of projects that have to be given up as a result of the cash flow drop. The other part of the investment effect is the extra-cost for funding projects that are still going to be undertaken and can no longer be financed using internal resources. These effects find an intuitive graphical representation in the context of Kaplan and Zingales' (1997) static model (see also, Hubbard, 1998; Fazzari, Hubbard, and Petersen, 2000). Fig. 4 plots the downward-sloping investment demand curve (D), which is the inverse of the marginal profitability of investment, as a function of the cost of funds. The curve S represents the supply of capital, which is flat at the level of the firm's cost of capital $(r)$ up to the amount of available internal funds $\left(W_{0}\right)$. Beyond $W_{0}$, the supply curve slopes upwards to capture the increasing premium to external finance due to the costs of asymmetric information. Because of the financing frictions, the equilibrium level of investment $\left(I_{0}\right)$ is below the first-best level $\left(I^{*}\right)$ and the cost of funds $\left(C_{0}\right)$ is above the firm's frictionless cost of capital. In other words, the firm is underinvesting The

\footnotetext{
${ }^{18} \mathrm{~A}$ component of the price reaction to a cash flow shock that is neglected by this framework is the increase in the cost of financial distress. In particular, a decrease in internal resources can increase the probability of default. Some of the results in the paper suggest that financial distress is not playing a role in the estimated effects.

${ }^{19}$ The choice to depict the curve D and the upward sloping part of S as straight lines is made for simplicity and does not interfere with the conclusions of this exercise.
} 
decrease in internal finance triggered by pension contributions can be represented as a shift to the left of the supply curve from $\mathrm{S}$ to $\mathrm{S}^{\prime}$, where $W^{\prime}$ is the new level of internal resources. The loss of surplus for the company due to the drop in internal finance is made of two pieces. First, the shaded triangle (AEE') captures the positive NPV of the forgone projects, as investment drops from $I_{0}$ to $I^{\prime}$. For financially constrained firms, this component captures the loss tied to Rauh's (2006) finding of a decrease in capital expenditures $\stackrel{20}{20}$ Second, the dashed area depicts the drop in value resulting from the fact that, due to the leftward shift of the supply curve, some of the surviving projects have to be funded at a higher cost $\left(C^{\prime}\right) ! 21$ The bottom line of this simple framework is that, in the presence of financing frictions, the value implications of a downward shift in cash flows are larger than the NPV of the forgone investment. These considerations become relevant when interpreting the magnitude of the estimated price reactions to contributions for constrained firms.

On the other hand, the investment effect is positive for firms that are overinvesting, i.e., companies for which the marginal investment project has negative NPV. In this case, paying down the pension liability subtracts the money from the hands of somewhat profligate managers. In other words, while transferring money to the pension plan is value-neutral in a frictionless world, it is beneficial for shareholders, if the firm is wasting their money.

Anecdotal evidence seems to suggest that an underfunded pension plan in some circumstances worked as an excuse to reduce potentially unproductive expenses. For example, due to the need to save cash for the $\$ 4.8$ billion pension contributions that it owed to the pension plan, in March 2002 General Motors revised a bonus plan for 3,500 of its top executives. Similarly, in July 2003, Twin Disc Corp., whose $65 \%$ funded pension plans had triggered statutory contributions, announced across-the-board wage reductions for corporate officers. While these examples do not prove the beneficial impact on value of transferring cash to the pension plan, they show the channels through

\footnotetext{
${ }^{20}$ Depending on the slopes of the curves and the magnitude of the shift, it is theoretically possible that the decrease in investment also extends to some projects that are initially internally funded (that is, $I^{\prime}$ ends up to the left of $W_{0}$ ). For these projects, the loss in NPV extends from $C^{\prime}$ to $r$.

${ }^{21}$ This component, in turn, is made of two pieces: the additional cost of the projects that are externally funded before and after the shift (rectangle ABGE'); the additional cost of the projects that were internally funded before the shift and are now externally funded (rectangle DFGH). In the case described in Footnote 20, this second piece is not present. I am grateful to François Degeorge for suggesting this interpretation.
} 
which the firm can disengage from potentially wasteful commitments thanks to pension contributions.

The considerations above suggest a way to highlight the relative importance of under- and overinvestment. In measuring the price reaction to pension contributions the empirical analysis tries to identify heterogeneity in this coefficient along the financial constraints and corporate governance dimensions. Governance provides an indirect measure of potential overinvestment, as in firms with more control on the managers' actions, the opportunity for empire-building is a priori smaller.

Analyzing price reactions circumvents a potential problem of the investment-cash-flow sensitivity approach. Kaplan and Zingales $(1997,2000)$ argue that the practice initiated by Fazzari, Hubbard, and Petersen (1988) of sorting firms according to a priori measures of financing constraints and comparing investment-cash flow sensitivities is not theoretically founded (see also,

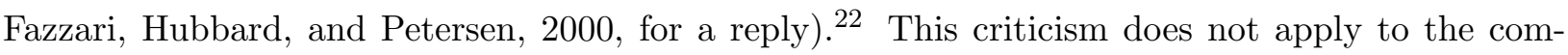
parison based on price reactions to a cash flow shock. In this case, the investment effect is an increasing function of the degree of financial constraints. $\frac{23}{23}$ The basic intuition is that, given decreasing marginal productivity of capital, a positive shift in internal resources produces a larger increase in value for a firm that is farther below the optimal investment level. It seems reasonable to believe that this intuition extends to dynamic models in which firms engage in precautionary savings to avoid future financing constraints (Almeida, Campello, and Weisbach, 2004; Whited and Wu, 2006; Hennessy and Whited, 2007)!24

There is an even more important advantage of studying price reactions. This metric provides the market's comprehensive assessment of the value of investment opportunities that are forgone because of the decrease in cash. In this sense, all types of investment are accounted for, including the ones that are not otherwise measurable (e.g., investment in human resources and other intangible

\footnotetext{
${ }^{22}$ Kaplan and Zingales' argument is corroborated by the results of the dynamic models in Moyen (2004) and Hennessy and Whited (2007).

${ }^{23}$ This statement can be easily proved in the context of Kaplan and Zingales' (1997) one-period model of investment. A technical appendix is available from the author upon request.

${ }^{24}$ Indeed, in a typical dynamic model, more constrained firms have lower investment-cash-flow sensitivities, because they face higher costs of raising finance. As a consequence, the shadow price of internal funds is higher in more constrained firms. I am grateful to Toni Whited for suggesting this intuition.
} 
assets). In addition, the drop in value accounts for the costs of external finance, which have been the subject of extensive studies (see, e.g., Hennessy and Whited, 2007).

\subsection{Identification and empirical specification}

The empirical studies of the effect of capital market imperfections on investment are confronted with the challenge of identifying exogenous variations in cash flows. If cash flow is correlated with future profitability, a link between cash flow and investment also results from a frictionless model in which investment is a function of expected profitability. In other words, changes in cash flows are an endogenous variable in the investment equation. In principle, controlling for investment opportunities with Tobin's $q$ should solve this problem. In practice, however, measurement error in $q$ is likely to invalidate this strategy (Erickson and Whited, 2000; Alti, 2003). Hence, the researcher needs to find variation in cash flows that is independent of investment opportunities.

A similar identification problem arises when trying to measure the projection onto market value of an expected change in investment due to a shift in internal resources. The price reaction to a cash flow shock depends on the firm's investment opportunities. Specifically, the same drop in cash is more costly for firms with good investment prospects. In principle, one would like to compare price reactions for firms with the same marginal profitability. However, if the likelihood of being hit by the cash flow shock correlates with investment opportunities, the measured price response is biased.

A further difficulty emerges if investment opportunities correlate with the chosen measures of financial constraints and empire-building opportunities. For example, a firm may be classified as financially constrained if it has a large need of funds (Hennessy and Whited, 2007). This need, in turn, can result from the availability of profitable investment opportunities. For this firm, the shadow price of cash flows is magnified by both investment opportunities and financial constraints. Identification requires the separation of the two effects! 25

This paper adopts the original identification strategy in Rauh (2006). He uses mandatory

\footnotetext{
${ }^{25}$ In the context of overinvestment, a comparable example is the following. Managers of firms that lack investment opportunities may have more incentives to divert cash. Here, the severity of agency conflicts and the lack of investment prospects both contribute to reduce the value of cash flows.
} 
contributions to a firm's defined benefit pension plans as a source of cash flow variation. These contributions depend on the funding status of the pension plans sponsored by the firm. The funding status is the difference between assets and liabilities in the plan. The firm has some leeway in deciding how much the plan should be funded. Moreover, it is reasonable to believe that the funding choice depends on the availability of cash flows and the profitability of the alternative uses of these funds. That is to say, the funding status is related to the firm's investment opportunities set.

A brief description of the functioning of defined benefit pension plans is given in Section 3 (see, in particular, Footnote [8) and a detailed treatment is provided in Rauh's article. For the present purposes, suffice it to say that mandatory contributions for underfunded plans, i.e., plans for which the liabilities exceed the assets set aside, are determined according to a non-linear function of the current funding status. Hence, analogously to the regression discontinuity approach in labor economics (see e.g. Angrist and Lavy, 1999), the identifying assumption in Rauh's approach is that the function that relates pension funding status to investment opportunities does not have the same kinks, jumps, and asymmetries as the function that relates the pension funding status to mandatory contributions. This assumption is easily satisfied, as the rules determining mandatory contributions follow an arbitrary structure. For example, contributions are zero for plans that are fully funded or overfunded, while there is no reason for discontinuity at the level of full funding in the relationship between funding status and investment opportunities. ${ }^{26}$ As a consequence, one can proxy for the unobservable investment opportunity set through linear and non-linear functions of the plans' funding status.

I use this approach to identify the component of the price reaction to a cash flow shock that is orthogonal to information about investment opportunities. In particular, my typical specification regresses abnormal stock returns $\left(R_{i t+1}\right)$ on the amount of mandatory contributions in the previous period $\left(M C_{i t}\right)$, an index of either financial constraints or corporate governance $\left(I_{i t}\right)$, the interaction

\footnotetext{
${ }^{26}$ This example is not exclusive, because the relationship between contributions and funding status displays kinks at different levels of funding (see Figure 2 in Rauh, 2006). Consequently, the identification comes from different points in the range of funding status, and not just from the comparison between zero and non-zero mandatory contributions at the full funding level, as one might suspect.
} 
between mandatory contributions and the index $I_{i t}$, linear and non-linear functions of the funding status $\left(F S_{i t}\right)$, and a set of control variables $\left(X_{i t}\right)$ :

$$
R_{i t+1}=\beta_{0}+\beta_{1} M C_{i t}+\beta_{2} M C_{i t} I_{i t}+\beta_{3} I_{i t}+\beta_{4} F S_{i t}+\beta_{5} X_{i t}+\varepsilon_{i t+1}
$$

As in Rauh's (2006) approach, controlling for the funding status identifies mandatory contributions as a cash flow decrease that is exogenous with respect to investment opportunities. Therefore, the coefficient $\beta_{2}$ captures the incremental effect of either financial constraints or empire-building on the price reaction caused by a cash flow drop, keeping investment opportunities constant. If $I_{i t}$ is a financial constraints index, and investment is sensitive to internal finance, then $\beta_{2}$ is predicted to be significantly negative. On the other hand, if $I_{i t}$ measures the potential for empire-building, a positive $\beta_{2}$ supports an overinvestment story in which part of the lost cash flows would have been wasted in negative NPV projects!27

Some papers identify a positive cross-sectional link between expected returns and measures of financial constraints. For example, Whited and Wu (2006) find evidence of a financial constraints factor. Moreover, following Gompers, Ishii, and Metrick's (2003) seminal paper, a number of studies point out a negative cross-sectional relationship between returns and indices of corporate governance (Bebchuck, Cohen, and Ferrell, 2004; Bebchuck and Cohen, 2005; Cremers and Nair, 2005). To control for these factors, which could interfere with the identification of the effect of interest, the index $I_{i t}$ also appears directly in Eq. 1.

The vector $X_{i t}$ includes Tobin's $q$ at the beginning of the period as a further control for investment opportunities. In all specifications, $X_{i t}$ includes time effects to control for aggregate phenomena that could affect both returns and mandatory contributions, such as a market downturn, and to partly absorb the cross-sectional correlation in the error terms $\frac{28}{28}$ Other controls are

\footnotetext{
${ }^{27} \mathrm{~A}$ positive $\beta_{2}$ could also be consistent with some predictions of Bertrand and Mullainathan's (2003) 'quiet life' hypothesis where managers refrain from making 'tough' decisions. As argued by Stein (2003), this theory generates overinvestment if the decision at hand is, for example, shutting down a poorly performing plant. Instead, it leads to underinvestment if the decision concerns whether to enter a new line of business.

${ }^{28}$ Instead, firm effects are not included, as the desired identification comes from cross-sectional variation in $I_{i t}$. Also, the inclusion of firm fixed effects entails a look-ahead bias that prevents the interpretation of the regression results as returns from a feasible trading strategy.
} 
meant to absorb the effect of characteristics that are known to affect asset prices, such as: size (market capitalization), book-to-market, past-12-months returns, and industry dummies. To allow for time-variation in the effect of characteristics, these variables are interacted with year fixed effects.

Concerning the dependent variable, given that there is no consensus on the correct model for risk, I report results using a number of different approaches for abnormal returns. First, I use raw returns and let the controls absorb expected returns that are related to risk and characteristics. Second, I compute beta adjusted returns by subtracting the return on the beta decile portfolio to which the stock belongs based on the estimate of its market beta from the prior two to five years of monthly data ending in December of year $t$. Third, I provide industry-adjusted returns, matching the stock return to one of the 17 industry portfolios from Prof. Ken French's Web site. Last, I adjust returns by matching each stock to one of the 125 portfolios that are formed by sequentially sorting firms into quintiles based on size, book-to-market, and momentum (past-12-months returns) according to the procedure in Daniel, Grinblatt, Titman, and Wermers (1997).

As the regressions are run on longitudinal data, one needs to be careful about the structure of the error terms in Eq. 1. Heteroskedasticity is certainly a concern given that returns on different stocks have different volatilities. Moreover, in spite of the risk adjustments and the inclusion of time effects, the residuals could still be cross-sectionally correlated. This is a typical issue in longrun event studies. Finally, although some of the specifications control for price momentum, one could still be wary of time-series correlation in the residuals. These considerations suggest that the Ordinary Least Squares (OLS) assumptions are unlikely to be satisfied by $\varepsilon_{i t}$ and the standard errors need to account for that.

Historically, the solution to cross-sectional correlation has been provided by the Fama and MacBeth (1973) procedure. More recently, clustering has been used as a remedy to either timeseries or cross-sectional correlation, as it allows the researcher to fully exploit the time-series and cross-sectional dimensions of the data in a pooled regression. However, as pointed out by Thompson (2006), clustering by firm or time presupposes independence along either of these two dimensions. Neither of these assumptions is granted in the present context. Fortunately, Thompson proposes 
a simple solution that corrects standard errors for both cross-sectional and time-series correlation. The resulting standard errors are also robust to heteroskedasticity and are shown to perform well at sample sizes that are comparable to the one in this study. Hence, I compute the standard errors throughout this work using Thompson's adjustment.

\section{Heterogeneity in price reactions}

\subsection{Price reactions to mandatory contributions}

Figs. 1 to 3 provide only a graphical description of the relation between contributions and returns. The main results in this paper are obtained through the regression analysis.

Table 3 reports the estimates from a shorter version of Eq. 1, in which the two variables involving $I_{i t}$ do not appear. I run the regression on pooled data. The variable $M C$ is expressed as a percent of market equity. So, the slopes on $M C$ have the interpretation of the dollar impact on firm value for a one-dollar contribution. The four panels in the table correspond to the different approaches to compute abnormal returns. The first column of each panel does not have controls for the funding status. Instead, the second column includes the aggregate funding status $(F S)$, while the third and fourth columns have separate controls for under- and overfunding and the first three powers of these variables, respectively.

Irrespective of the chosen return adjustment and the set of controls for investment opportunities, the table suggests that the predictive power of $M C$ for abnormal returns is strongly significant. Across the specifications in Table 3, this effect implies that a one-dollar increase in contributions reduces shareholder value by about $\$ 0.99$. One should remember that in a frictionless world the effect should be zero, as contributions represent a shift from cash to assets in the pension plan, which is a fully owned subsidiary of the company.

Instead, these findings suggest that the average firm in this sample is characterized by a strongly negative investment effect. Hence, these results provide preliminary evidence that the negative impact of mandatory contributions on value is magnified by the presence of costly external finance.

In all panels, the comparison between the first and the last columns, which has the largest set of controls, highlights the likely role of investment opportunities. In the first specification, the 
return reaction is always smaller in absolute value. One can interpret this result as suggesting that firms that are more likely to pay contributions are those with lower marginal profitability. As argued in Section 4, the investment effect for these companies is smaller in absolute value and the estimated negative return reaction is upward biased. This bias generates the need to control for investment opportunities. Moreover, the conclusion is consistent with Rauh's (2006) finding of a positive correlation between funding status and investment opportunities.

Overall, Table 3 suggests that mandatory contributions significantly predict negative abnormal returns over the following year. These results validate Franzoni and Marin's (2006a) conjecture that part of their effect is due to the market's reaction to mandatory contributions that are imposed onto firms sponsoring underfunded pension plans. More important for the present purposes, this evidence legitimates the interpretation of mandatory contributions as a shift in internal resources that is (at least partly) unanticipated by the market.

\subsection{Price reactions and financial constraints}

Next, I directly investigate whether the market's response to mandatory contributions varies across firms displaying different degrees of financial constraints. As mentioned above, the purpose is to assess to what extent investors impound into prices the fact that a shift in internal funds obliges financially constrained firms to face costly external finance and to give up positive NPV investment projects.

I replace the interaction between the index $I_{i t}$ and mandatory contributions in Eq. 1 with the product between $M C$ and a dummy variable denoting firms that in year $t$ rank in the top $25 \%$ of the distribution of the index (Hi FC). Hence, the coefficient on this interaction measures the incremental price reaction to a given amount of contributions relative to the firms in the bottom three quarters of the distribution, for which the price reaction is captured by the slope on $M C$. The (standardized) financial constraints index also appears directly in the regression.

The four panels of Table 4 report the estimates based on the different approaches to compute abnormal returns. One can interpret the slope on the interaction variable as the total dollar impact of a one-dollar increase in contributions on firms in the top FC group. The evidence in Table 4 is largely consistent with a magnifying effect of financial constraints on price reactions to mandatory 
contributions. Across panels, constrained firms (Hi FC) display larger price reactions (in absolute value) than unconstrained firms. In all specifications, the effect is strongly significant for the three indices ( $p$-values below 1\%). Across panels and specifications in Table 廿 the dollar effect of a one-dollar increase in contributions for constrained firms is $\$ 1.30$ on average. For unconstrained firms, the impact of contributions is in general not statistically different from zero (slope on $M C$ ). This evidence corroborates the conjecture that the investment effect should not be present in the absence of frictions.

The slopes on the top FC groups tend to be quite close across FC indices in spite of the low correlation among these scores. This evidence is due to the fact that the three indices are more likely to capture similar firms in the Hi FC group than in the rest of the distribution. Specifically, although the unconditional correlations among the three FC indices tend to be low, they are substantially higher when conditioning on the firms in the Hi FC group.

In interpreting the magnitude of the estimated price reactions, one should keep in mind the discussion in Section 4, which identifies two components of the negative investment effect for constrained firms. First, a number of marginal projects that could be funded using internal resources have to be abandoned when cash flows are shifted towards the pension plan (the shaded triangle in Fig. (4). Second, because of the increased dependence on external finance the cost of capital for the remaining investments rises (the dashed area in Fig. (4). An accurate assessment of the relative importance of the two effects would require the calibration of a fully specified investment model, which is outside the scope of this paper. Still, a simple back-of-the-envelope calculation can provide some intuition.

As a first approximation, I assume that only the first effect is present. That is, the price reaction for constrained firms (on average $\$ 1.30$ per dollar of contributions) is due to the NPV of the forgone investments. Moreover, based on Rauh's (2006) finding of a $\$ 0.60$ to $\$ 0.70$ marginal effect of contributions on capital expenditures, I assume that a one-dollar contribution decreases investment by $\$ 0.65$. Then, with a simple calibration of the growth rate of the firm's cash flows and the cost of capital, I can conclude that the internal rate of return (IRR) of the forgone projects 
ranges between $13.7 \%$ and $20.2 \% \underline{29}$

Although plausible, these estimates should be considered as an upper bound to the IRR of the forgone investment projects. More realistically, only a fraction of the price reaction should be imputed to the NPV of the lost investments. As an example, one could consider a case like Fig. 4 in which the loss of surplus due to the first effect is less than one third of the total reduction in firm value ${ }^{30}$ Then, if the NPV to be explained is at most one third of $\$ 1.30$, the same approach suggests that the IRR of the forgone projects ranges between $9.8 \%$ and $13.3 \%$. Overall, this simple exercise suggests that the estimated return reactions are consistent with realistic investment behavior.

As a final remark, the supporting evidence in Table 4 for the existence of a financial constraints factor in returns, which should be captured by the slope on the FC index, is mixed at best. Only the WW index has a positive impact on returns that comes close to statistical significance. This finding confirms the results in Whited and $\mathrm{Wu}$ (2006), who show that their measure is a better proxy than the two other scores to identify a systematic effect of financing frictions in returns. It must be stressed, however, that the lack of consensus in the literature on the existence of a financial constraints factor does not interfere with the research design of the paper. The drop in cash caused by mandatory contributions is likely to qualify as an idiosyncratic shock. In this sense, the price reactions that are generated by pension contributions may be washed out in a well-diversified portfolio. Nevertheless, these abnormal returns are still informative on the market value of forgone investments at firm level, which is the only focus of this work.

\footnotetext{
${ }^{29}$ One has to compute the IRR of a $\$ 0.65$ investment, whose stream of cash flows has an NPV that equals $\$ 1.30$. I assume an infinite stream of cash flows growing for five years at the analysts' average consensus forecast of long term growth for the firms in the constrained group (13.7\% from the Institutional Brokers' Estimate System (IBES) data set). For the remaining horizon, cash flows are assumed to revert to the growth rate of the rest of the economy (that is, I use the trend rate of nominal gross domestic product (GDP) growth, which is about $5.3 \%$ using the seasonally adjusted nominal GDP series between the first quarter of 1990 and the first quarter of 2008 from the St. Louis Federal Reserve Bank). To estimate the nominal cost of capital, I use the risk free rate in this sample of about 5\%, I take a beta of 1 (which corresponds to the observation for the average firm in the sample) and postulate an equity premium between $3 \%$ and $5 \%$. Using CAPM, the cost of capital ranges between $8 \%$ and $10 \%$.

${ }^{30}$ As noted, the case depicted in Fig. 4 has $I^{\prime}$ to the right of $W_{0}$. Furthermore, the decrease in investment (segment $\mathrm{AE}$ ) is always smaller than the fall in internal resources (segment DH). Hence, one can conclude with certainty that the triangle AEE' is less than half of the shaded area.
} 


\subsection{Price reactions and corporate governance}

From the above results one concludes that the market reacts more strongly to cash flow shocks that hit financially constrained firms. This evidence is consistent with an underinvestment story in which investors anticipate that internal finance is more valuable for constrained companies. In what follows, I use the same framework to tackle the issue of overinvestment.

In the main application, I use the governance index developed by Gompers, Ishii, and Metrick (2003) and test whether price reactions to mandatory contributions vary across different levels of shareholders' protection. The hypothesis is that the same cash flow drop should be less costly for firms with weaker shareholders' rights, as part of it would be wasted in empire-building activities.

Gompers, Ishii, and Metrick (2003) admit that their study cannot make strong claims about causality because of the lack of random assignment. Specifically, weak firms could self-select into the group of companies with low shareholders' protection. Then, the positive link between good corporate governance and future performance would be the outcome of this endogeneity. Fortunately, this criticism is not likely to apply to the present set-up, where one can control for investment opportunities through the firm's funding status.

Given the evidence from the previous subsection that financial constraints matter for price reactions, in a fully specified model, it makes sense to take this effect into account. Hence, I nest the costly-external-finance and empire-building models into one specification by including the FC index and its interaction with mandatory contributions. That is to say, the preferred specification is:

$$
\begin{aligned}
R_{i t+1}= & \beta_{0}+\beta_{1} M C_{i t}+\beta_{2} M C_{i t} G_{i t}+\beta_{3} G_{i t}+\beta_{4} F S_{i t}+\beta_{5} X_{i t} \\
& +\gamma_{1} M C_{i t} F C_{i t}+\gamma_{2} F C_{i t}+\varepsilon_{i t+1} .
\end{aligned}
$$

$\mathrm{G}$ enters the regression as a set of dummy variables for firms in the three terciles of the G distribution for each year. Observations in the High G group are those with the lowest quality of governance according to this index. Hence, if poor governance determines overinvestment, one should expect the slope on the interaction between High $\mathrm{G}$ and $M C$ to be positive. Once again, the slope on $M C$ and the interaction terms can be interpreted as dollar effects for a one-dollar contribution. Table 5 
reports the estimates of this model and shorter versions.

By imposing the availability of the governance indices, the sample is limited to 4,157 firm-year observations on 827 firms. In interpreting the following results, one has to keep in mind the evidence from Table 1 suggesting that firms in this restricted sample are $40 \%$ larger than the original sample. Also, they are less financially constrained.

The last remark partly explains why the unconditional price reactions in the first column of each panel in Table 5 are hardly different from zero. Only in the first column of Panel A does the slope on $M C$ achieve $5 \%$ significance. In other words, the evidence in Table 5 suggests that the negative investment effect caused by financial constraints is less strong in this sample of large firms than in the whole sample (Table 3).

A complementary explanation for this finding emerges from the analysis of the main result of the table. The second column of each panel highlights a strong governance-related heterogeneity in price reactions. The slope on the interaction between High $\mathrm{G}$ and $M C$ is always significant at the $1 \%$ level. This finding suggests that empire-building strongly mitigates the negative impact on value of financial constraints. The insignificant unconditional price reactions that are recorded in the first column of each panel are the result of the combination of these two forces.

Instead, the slope on $M C$ in the second column captures the effect of contributions on wellgoverned firms (Low G) unconditional on the level of the FC indices. Because the funds in these companies are not subject to empire-building managers, this slope captures the negative investment effect resulting from the average level of financing constraints to which the firms are exposed. This fact explains why these slopes are more negative than in the first columns, although only marginally significant.

The last three specifications in each panel explicitly condition on the FC indices. The main result of this table remains intact, as the interaction between the High G dummy and mandatory contributions is still strongly significant. As anticipated, the evidence for financial constraints in this sample is somewhat weaker. Among the three indices, only the WW index generates significant estimates.

Given that these models condition on financial constraints, the slope on $M C$ is now on average 
closer to zero than in the second column, as it captures the effect of an increase in contributions for unconstrained and well-governed firms.

Focusing on the second column of each panel, the average attenuating effect of poor-governance (High G) for a one-dollar increase in contributions is $\$ 4.70$. To gauge the total value of cash flows in poorly governed firms unconditional on financial constraints, one has to add back the baseline effect (slope on $M C$ in the same specifications). The net effect is positive on average $(\$ 3.20)$, but a statistical test rejects the null that it is significantly different from zero.

As argued in Section 4, the positive (although insignificant) investment effect should not be considered as a priori counterintuitive. One should remember that contributions are not leaving the firm. Rather, they are used to pay down the pension liability. In this sense, transferring money to the pension plan is neutral from the point of view of equity. What affects shareholder value is the fact that in empire-building companies the funds are subtracted from negative NPV projects. For this reason, pension contributions can turn out to be good news for equity-holders in poorly governed firms.

One may want to compare the magnitude of these results to previous studies that focus on the value of cash across measures of the quality of governance. Specifically, Dittmar and Mahrt-Smith (2007) estimate the change in value that follows from the annual change in the stock of cash keeping everything else constant. In the absence of distortions to investment, a one-dollar change in cash should trigger a one-dollar change in firm value. Instead, they find that $\$ 1$ in a poorly governed firm (top tercile of the distribution of $\mathrm{G}$ ) is worth only $\$ 0.42$. On the other hand, one dollar is valued $\$ 1.62$ in a well-governed firm (bottom tercile). Relative to their results, I find a larger gap between well- and poorly governed firms, which suggests a stronger impact of overinvestment. This difference in magnitude likely depends on the fact that these authors focus on the change in the overall stock of cash, whereas I only look at marginal variations in cash flows. A small variation in cash flows is arguably an easier prey for empire-building managers than the overall change in the stock of cash.

In the remainder of the section, I examine the robustness of the previous results to alternative governance measures. First, as in Dittmar and Mahrt-Smith (2007) and Masulis, Wang, and Xie 
(2007), I extend the analysis to the index developed by Bebchuck, Cohen, and Ferrell (2004) who focus on a subset of six provisions out of the 24 originally used by Gompers, Ishii, and Metrick (2003). Then, as in Dittmar and Mahrt-Smith (2007), I consider the ownership share held by institutional blockholders.

Table 6 replicates the structure of Table 5 using the entrenchment index (BCF), which is measured as the number of ATPs out of a total of six. Overall, the magnifying effect of poor governance for the price reactions following the pension contributions is still present, although the results are somewhat less statistically significant. Across panels, a one-dollar increase in contributions generates about $\$ 2.20$ of savings on average from negative NPV projects that are not undertaken, for each ATP in the BCF index. Accounting for the baseline effect unconditional on financial constraints (slope on $M C$ in the first column of each panel), a one-dollar contribution causes a total increase in value of about $\$ 4.23$ for firms in the top tercile of the BCF distribution (average BCF $=4.2$ ). This effect is not statistically different from zero. As in the previous table, the evidence suggests that the marginal value of cash flows in poorly governed firms is indistinguishable from zero, while it is significantly different from the value of funds in well-governed companies.

Table 7 reports the estimates with the blockholdings index as a measure of the quality of governance. In this case, higher blockholdings proxy for better governance. So, one should expect $\beta_{2}$ to be negative in Eq. 2. The estimates confirm this conjecture, as the slope on the interaction between $M C$ and Block is negative and significant. Across specifications, a one-dollar increase in contributions is $\$ 0.18$ more costly for each percentage point of additional institutional ownership. This result suggests that cash flows are more valuable in firms with larger institutional holdings, supposedly because there is more monitoring on the use of funds. Conversely, in an unmonitored firm (bottom tercile of the Block distribution with average Block about equal to $0.41 \%$ ), a onedollar drop in cash flows causes a $\$ 1.07$ total increase in value (estimate from the average slopes in the first columns of each panel in Table 7). Once again, this effect is not statistically different from zero.

To summarize, the main conclusion from Tables [5, 6, and 7 is that the market's reaction to a cash flow shock varies across different dimensions of corporate governance. If one is willing 
to assume that these indices measure the exposure to managers' empire-building behavior, the evidence suggests that the market anticipates an economically important role of overinvestment. The magnitude of this effect is stronger than that found in previous studies. Moreover, the effect of financial constraints remains present alongside the empire-building dimension. Hence, a description of reality that possibly emerges from the data is one where the market considers both over- and underinvestment as relevant outcomes of firm behavior.

\section{Underinvestment vs. overinvestment}

The empirical evidence suggests that the market differentiates firms across the financial constraints and governance dimensions when reacting to a cash flow shock. The proposed interpretation of these findings relates the value of the internal resources for a company to the real distortions generated by costly external finance and empire-building behavior. Although these distortions have opposite implications for investment, they can be nested in a model that admits both under- and overinvestment (see Stein, 2003). The question, then, is which friction prevails empirically.

The present set-up allows one to partially address this question for the firms that are included in this study. Specifically, for each company one can compute the aggregate price reaction to the cash drain caused by pension contributions. This return results from two counteracting forces: the negative investment effect due to financial constraints, and the positive investment effect due to empire-building. For some firms the empire-building problem can be so serious that they operate in the overinvestment region and the net price reaction is positive. On the other hand, if the aggregate price reaction is negative, one can conclude that the market esteems underinvestment as prevalent for a given company.

The estimates of the unconditional effect of mandatory contributions from Tables 3 and 5 allow one to infer the net investment effect for the average firm in the sample. These results are in Section 5 and I summarize them here. First, the large negative slopes on $M C$ in Table 3 suggest the prevalence of underinvestment in the whole sample. Second, when focusing on the set of large firms for which the governance index is available, the unconditional effect of contributions is mostly 
insignificant (slope on $M C$ in the first column of each panel of Table 5). Hence, one would tend to infer a smaller role for underinvestment in the restricted sample.

These unconditional estimates represent a summary measure of the combined effects of underand overinvestment on the average firm. If the distribution of these effects across firms is very skewed, or if the financial constraints and governance indices correlate with contributions, the price reaction for the average company is not necessarily informative on the allocation of these distortions in the population. Hence, looking at price reactions conditional on financial constraints and governance can provide additional information. This is the focus of the next exercise.

In Eq. 2, the impact of the cash drain is measured through the slope on $M C$ and through the interactions of $M C$ with the FC index and the governance index. This suggests a way to estimate the firm-level price reaction (PR) following from a one-dollar increase in $M C$ :

$$
P R_{i t}=\hat{\beta}_{1}+\hat{\beta}_{2} G_{i t}+\hat{\gamma}_{1} F C_{i t}
$$

The sign of PR for a given firm in a given year reveals if under- or overinvestment is the prevalent distortion for that observation. I obtain the relevant slopes by estimating Eq. 2 for each of the three FC indices in the sample of large firms where $\mathrm{G}$ is available $\stackrel{31}{3}$

Fig. 5 plots the distributions of PR across firm-year observations for the three FC indices. In all cases, the median corresponds to a positive value for PR suggesting that overinvestment is the prevailing distortion in this sample. Using the WW index, $44 \%$ of firm-year observations display a negative total price reaction to a cash flow shock. This is the highest cut-off point among the three indices, consistent with the finding that only the WW index captures a significant effect of financial constraints in this restricted sample (Table 5). The cut-offs are $36 \%$ and $30 \%$ with the CLEARY and $\mathrm{KZ}$ indices, respectively. Hence, as anticipated, in this restricted sample of large companies, the market seems to attribute a slightly higher importance to overinvestment.

Given that $\mathrm{G}$ is not universally available, one cannot perform the same exercise for the entire

\footnotetext{
${ }^{31}$ For this exercise, I use the specification where the dependent variable is the raw return. Using the other approaches to compute abnormal returns yields qualitatively similar results. Also, G and the FC indices enter the estimated specification as a continuous variables, as opposed to a set of dummy variables. Still, the estimates are not qualitatively different from the ones reported in Panel D of Table 5
} 
sample. Still, in consideration of the strongly significantly negative unconditional price reaction for the average firm (Table 3) and the apparent symmetry of the distributions of PR, one can confidently infer that underinvestment prevails in a sample of firms that is less tilted towards large companies.

These observations are in line with previous evidence. For example, McConnell and Muscarella (1985) find that the average price reaction to the announcement of capital expenditures is positive, consistent with the marginal project having a positive NPV (underinvestment). Instead, it is negative in the oil industry where, according to Jensen (1986), there was systematic overinvestment in those years.

The ability to interpret the heterogeneity in abnormal returns as the market response to forgone investment projects relies on whether the chosen indices are able to effectively capture exposure to financial constraints and empire-building, as assumed so far. While one cannot directly test this hypothesis, it is still possible to verify that the identity of the firms that rank differently according to estimated price reactions to contributions conforms to the theoretical priors on companies that under/overinvest.

To this purpose, I rank the firm-year observations into three groups by the levels of PR (bottom $25 \%$, intermediate two quarters, and top $25 \%$ of the distribution). According to the proposed interpretation of $\mathrm{PR}$, the observations in the bottom group are the most prone to underinvestment and the least to overinvestment. The opposite is true for the top group. Then, I look at summary statistics on several firm characteristics for the three PR groups constructed using the three alternative FC indices. The results are in Table 8 .

By construction, there is positive correlation between PR and G. For the same reason, the correlation is negative between $\mathrm{PR}$ and the FC indices. While the positive relation between PR and $\mathrm{BCF}$ is a consequence of the high correlation of the latter with $\mathrm{G}$, the negative link between the Block index and PR is an independent piece of good news. In fact, the blockholders index is not highly correlated with G (see Table 1). Hence, finding that it is well-aligned with a measure of overinvestment based on G suggests that the two governance indices capture similar phenomena.

Also interesting, the firms that rank higher by PR have a better funding status $(F S)$ and, as 
a consequence, pay lower mandatory contributions $(M C)$. This fact could be evidence that the companies that are more prone to overinvestment (high PR) are those whose cash flows are not committed to the pension plan, consistent with Jensen's (1986) free-cash flow hypothesis.

As one would expect from companies that overinvest, high-PR firms are bigger, older, and past winners according to the momentum variable (Mom). The same companies are growth rather than value stocks. On the other hand, the firms that are predicted to underinvest have lower analyst coverage and are less likely to have debt ratings, consistent with asymmetric information explanations for costly external finance.

Firms that appear to overinvest can afford the highest R\&D and capital expenditures. As for the remaining variables, they do not allow one to draw definite conclusions. Their ranking across PR-groups is affected by their role in the construction of the FC indices, which in turn enter the definition of PR.

Tobin's $q$ deserves special attention, as it is used in a number of studies to capture potential overinvestment. Specifically, managers in low- $Q$ companies are believed to have fewer opportunities for profitable investments and to be, therefore, more likely to waste cash (see, e.g., Officer, 2007). The pattern in Table 8 highlights a positive link between $q$ and PR. However, this is the result of the univariate analysis and it disappears in multivariate regressions that control for other firm characteristics, notably size. In these regressions, a significantly negative relation can be estimated between $\mathrm{PR}$ and $q$, which is consistent with the prediction for overinvesting companies (results not reported).

To summarize, consistent with the theoretical priors, the firms that are predicted to overinvest are larger, older, and have lower institutional ownership. These observations and other consistent results in Table 8 allow additional confidence on the interpretation of the heterogeneity in abnormal returns as the market's response to under/overinvestment.

\section{Robustness checks}

The first set of robustness checks focuses on the results based on the financial constraints indices. Specifically, I add further controls to the original specification from Table 4 and estimate the model 
on subsamples. Table 9 reports the slopes on the interaction between $M C$ and the top financial constraints group dummy for the three FC indices. The different panels correspond to different approaches to compute abnormal returns.

The discussion in Section 4 points out the need to control for investment opportunities. The rationale is that the same cash flow shock can impact value differently depending on a firm's investment prospects. In this sense, the total price reaction may also depend on the interaction between investment opportunities and marginal contributions. Omitting this variable can cause a bias in the estimation of the effect of interest 32 Fortunately, one can avoid this problem by controlling for the interaction between $M C$ and a proxy for investment opportunities; here, I use $F S$. The estimates in row 1 of Table 9 reveal that the inclusion of this potentially omitted variable does not affect the main results. Incidentally, the (unreported) slopes on the interactions between $M C$ and $F S$ are never significant.

It could be the case that the same cash flow shock generates heterogeneous return reactions because of a discount rate effect. In particular, the present value of the forgone investment projects may differ, because cash flows are discounted at different rates. Then, if the index was correlated with the discount rate, the interaction between the $\mathrm{FC}$ index and $M C$ would capture this effect. However, it is likely the case that more constrained firms are more risky and have higher discount rates. In such circumstances, the discount rate effect would actually weaken the magnifying effect of financial constraints for price reactions. In any event, to verify whether this aspect plays any role, I estimate models that include the interaction of $M C$ with $\mathrm{BM}$ and size, as proxies for discount rates. The results are in rows 2 and 3. Overall, the coefficient of interest is not significantly impacted by the inclusion of these controls.

On a similar note, if the risk adjustments are not appropriate, leverage may be a more likely candidate to capture the discount rate effect. When one augments the specification by including leverage (TLTD) and its interaction with $M C$ (row 4), the results are not affected!33

\footnotetext{
${ }^{32}$ See, for example, Section 4.3.3 in Wooldridge (2002).

${ }^{33}$ Another potentially relevant effect of leverage is related to how the increase in firm value is allocated between equity and debt holders. Equity can be modeled as a call option on the value of the firm with strike price at the face value of debt. As a function of the 'moneyness' of the option, an increase in value through a positive cash flow shock
} 
Given the potential overlap between financing constraints and financial distress, one may be concerned that the results are driven by an increase in the cost of financial distress induced by the cash flow shock. The control for leverage partly rules out an effect of financial distress. As a further robustness check, I use interest cover (COVER) as a proxy for financial soundness and include it directly and interacted with $M C$. The results in row 5 further depose against a significant role for financial distress.

The empirical strategy is built to capture the abnormal returns in the year that follows the payment of pension contributions. This approach could be invalidated if the speed at which information is impounded into prices differs across firms in a way that is correlated with the FC indices. For example, one could imagine that the information about a given amount of contributions spreads less rapidly for smaller firms. At the same time, small firms are likely to appear as financially constrained. In this case, the interaction between $M C$ and the Hi FC dummy would be capturing price informativeness rather than financial constraints. Similarly, there could be a fraction of mandatory contributions that is anticipated by the market based on the pension information from previous years. This fact can be problematic for the strategy in this paper to the extent that the degree of anticipation is correlated with the measures of financial frictions. For example, one may argue that it is harder for the market to predict future mandatory contributions for small firms on which there is less information. At the same time, small firms are arguably more financially constrained. To partly control for these possibilities, I introduce interactions of $M C$ with variables that proxy for the speed of information revelation such as firm size (already discussed above) and the average number of analysts following the company over the year (row 6, Table 9). The coefficients of interest retain significance in general. Overall, these results suggest that the identification is not affected by the controls for information. Also, this robustness check should mitigate the concern that the return measurement window does not fully capture the price reaction. To the extent that the bias in the window is not correlated with the speed of information impounding, the interpretation of

will be allocated more to equity than to debt. Consistent with this idea, Faulkender and Wang (2006) find that cash is more valuable in firms with low leverage. Given that this effect operates in the opposite direction relative to the effect of financial constraints, it makes the finding of a financial constraints effect even more robust. 
the coefficients of interest in terms of heterogeneity in financial constraints and empire-building remains valid.

To identify mandatory contributions as a cash flow shift orthogonal to investment opportunities one has to control for the exact function that links investment opportunities to the funding status. The specifications in Table 4 only include a linear function of the firm's aggregate funding status $(F S)$. Following Rauh (2006), the specification in row 7 adds separate controls for the funding status of the over- and underfunded plans sponsored by the firm and for the second and third powers of these variables. In spite of the high correlation of the included variables with $M C$, there is still sufficient independent variation in mandatory contributions to identify the effects of interest, which remain significant.

The analysis by subsamples (rows 8 and 9) reveals that the effect of financial constraints is significant in both subsamples and, in many specifications, it is somewhat stronger in earlier years.

Table 10 replicates the sensitivity analysis of Table 9 with a focus on the governance index $(\mathrm{G})$. The original specifications are the ones in Table 5 that include the FC indices (slope on $M C \times$ High G). Overall, the significance of the governance effect on abnormal returns is not impacted by the controls. The results seem to be stronger in the early subsample, but significant estimates are obtained also in the later years.

\section{Conclusions}

In a frictionless world where managers maximize shareholder value, if a firm shifts cash towards less liquid assets, equity is not impacted. Many firms in the real world, however, face a premium for external finance, i.e., they are financially constrained. In this case, cutting cash flows curtails productive investment and equity is negatively impacted. On the other hand, if managers pursue their own interests (i.e., they overinvest), the negative impact on equity is attenuated. At the limit, reducing cash can increase value, if it prevents negative NPV projects from being undertaken.

These arguments suggest the empirical strategy of the paper. The goal is to shed light on the extent to which the observed sensitivity of investment to financial slack depends on either under- or overinvestment. To this purpose, one can focus on the price reaction to the payment of mandatory 
pension contributions to a firm's defined benefit pension plan. In the absence of frictions, no price reaction to contributions is expected, because the money is transferred to a fully owned subsidiary. A non-zero price reaction is likely to reveal a deviation from a frictionless model of investment. Furthermore, by studying the magnitude of estimated effects along the financial constraints and empire-building dimensions, one can gauge the relative importance of under- and overinvestment.

The advantage of mandatory contributions is that they allow the researcher to identify cash flow variation that is orthogonal to investment opportunities. Because mandatory contributions are determined by the law according to an arbitrary schedule, one can control for marginal profitability by using the pension plan funding status (i.e., the difference between assets and liabilities in the plan), which is an observable outcome of the firm's decision process.

I measure financial constraints with three indices that are common in the literature: the Whited and Wu (2006) index, the Cleary (1999) index, and the Kaplan and Zingales (1997) index. To capture empire-building, I use the Gompers, Ishii, and Metrick (2003) index of corporate governance, a measure of managerial entrenchment (Bebchuck, Cohen, and Ferrell, 2004), and institutional blockholdings (Cremers and Nair, 2005 and Dittmar and Mahrt-Smith, 2007). Following Jensen's (1986) free-cash flow hypothesis, the assumption is that high takeover protection as well as low institutional monitoring give the managers opportunities to pursue empire-building projects.

The data reveal that the market reacts significantly more strongly to a drop in cash that affects a financially constrained firm, irrespective of the chosen measure of constraints. Across specifications, a one-dollar drop in cash causes a $\$ 1.30$ total decrease in value for a constrained firm, whereas the effect is indistinguishable from zero for an unconstrained firm. I interpret this difference as the incremental cost of external finance and the value of forgone investment projects for the financially constrained company.

At the same time, the evidence suggests that low monitoring on the managers' actions brings about a significant destruction of value. Specifically, the price reaction to a given drop in cash is significantly smaller in absolute value for firms with entrenched managers and less institutional presence. The amount of overinvestment that is implied by these estimates is larger than that found in previous studies. I impute the large magnitude to the fact that the analysis focuses on 
marginal variations in the stock of cash.

Next, the paper addresses the question of which investment distortion prevails. The idea is to look at the aggregate price reaction to contributions at firm-level conditioning on both financial constraints and the quality of governance. In the subsample of large firms for which governance data are available, overinvestment seems to be somewhat more important. Instead, for the entire sample, which more closely resembles the universe of listed firms, underinvestment is by far more relevant. This evidence is consistent with the common sense that large firms are less constrained and have more cash flows to waste.

Finally, firms that are predicted to overinvest appear to be larger, older, more covered by analysts and rating agencies, and to display less institutional ownership. These results conform with the theoretical presumptions concerning overinvesting companies. For this reason, they strengthen the conclusions of the paper.

Before concluding, it is worth mentioning the potential asset pricing implications of the results in the paper. A number of studies find evidence of factors related to financial constraints in asset prices (Perez-Quiros and Timmermann, 2000; Lamont, Polk, and Saa-Requejo, 2001; Gomes, Yaron, and Zhang, 2006; Whited and Wu, 2006). On a different front, some literature uses measures of the quality of corporate governance in the firm to predict returns (Gompers, Ishii, and Metrick, 2003; Bebchuck, Cohen, and Ferrell, 2004; Bebchuck and Cohen, 2005; Cremers and Nair, 2005; Cremers, Nair, and John, 2005). Because of the idiosyncratic nature of pension contributions, the results in the paper do not allow one to draw direct inference on the presence of factors related to financial constraints and governance. Still, the evidence suggests that these two dimensions generate heterogeneity in price reactions to a given shock. Given this finding, it is legitimate to believe that similar heterogeneity would show up in price reactions to shocks that, unlike pension contributions, qualify as systematic cash flow news. If this belief is correct, then the results in the paper provide indirect support for the existence of risk factors related to financial constraints and corporate governance. 


\section{Appendix. Variable definitions}

This appendix provides definitions for the variables that are used in the empirical analysis and that are not already defined in Section 3 .

Excluding financial firms (three-digit SIC codes starting with 6), I use Compustat and CRSP data to construct Tobin's $q$, size, book-to-market (BM), momentum returns, and industry dummies. All of these variables are winsorized at the first and ninety-ninth percentiles. Size is market capitalization. Momentum is captured by the compound return over the 12 months before June of year $t+1$. Industry dummies are created using three-digit SIC codes. These variables are constructed at the end of year $t$ and matched to returns between July of year $t+1$ and June of year $t+2$, except for momentum and size, which are computed in June of year $t+1$.

Book-to-Market (as in Fama and French, 1993) is book value of equity at the end of the fiscal year (BE) divided by market capitalization in December. BE is stockholders' equity, plus balance sheet deferred taxes (Compustat item 74) and investment tax credit (item 208, if available), plus post-retirement benefit liabilities (item 330, if available), minus the book value of preferred stock. Depending on availability, I use redemption (item 56), liquidation (item 10), or par value (item 130), in that order, for the book value of preferred stock. I calculate stockholders' equity used in the above formula as follows. I prefer the stockholders' equity number reported by Moody's (data on Ken French's Web site), or Compustat (item 216). If neither one is available, I measure stockholders' equity as the book value of common equity (item 60), plus the book value of preferred stock. If common equity is not available, I compute stockholders' equity as the book value of assets (item 6) minus total liabilities (item 181).

Tobin's $\boldsymbol{q}$ is defined as: [Total Assets (item 6) + CRSP December Market Equity - Common Equity (item 60) - Deferred Taxes (item 74)]/Total Assets.

Kaplan-Zingales Index. The index is defined normalizing variables by total assets in the previous period:

$$
-1.001909 C F+3.139193 T L T D-39.36780 T D I V-1.314759 C A S H+0.2826389 Q,
$$


where $C F$ is the ratio of cash flow (item $18+$ item 14) to total assets (item 6), TLTD is the ratio of total long-term debt (item 9) to total assets, $T D I V$ is the ratio of total dividends (item $19+$ item 21) to book assets, $C A S H$ is the ratio of cash (item 1) to total assets, and $Q$ is Tobin's $q$.

Whited-Wu Index. The index is:

$$
0.938407-0.091 C F-0.062 D I V P O S+0.021 T L T D-0.044 L N T A+0.102 I S G-0.035 S G,
$$

in which DIVPOS is an indicator that equals one if the firm pays dividends, and zero otherwise, $S G$ is own-firm real sales growth, $I S G$ is three-digit industry sales growth, and $L N T A$ is the natural log of total assets.

Cleary index. The index is constructed as in Hennessy and Whited (2007) on the basis of Table II in Cleary (1999):

$$
\begin{aligned}
& -0.11905 C U R A T-1.903670 T L T D+0.00138 C O V E R+1.45618 I M A R G+2.03604 S G \\
& -0.04772 S L A C K,
\end{aligned}
$$

in which $C U R A T$ is the ratio of current assets to current liabilities; the numerator of $C O V E R$ is earnings before interest and taxes (item 13 - item 14), the denominator of COVER is [interest expense (item 15) + preferred dividend payments (item 19)]/ (1 - Tax Rate), where Tax Rate is: item 16/(item 13 - item 14 - item 15); IMARG is the ratio of net income (item 18) to sales (item 12); the numerator of $S L A C K$ is: cash + short-term investments $+0.5^{*}$ (inventory) $+0.7^{*}$ (accounts receivable) - short term loans, and denominator of $S L A C K$ is net fixed assets. Cash plus short term investments is item 1 ; inventory is item 3; accounts receivable is item 2; short term loans is item 196; and net fixed assets is item 8. Extreme values of these variables are winsorized as in Cleary (1999). I multiply the Cleary index by -1 so that it is increasing in the likelihood of facing costly external finance.

The three financial constraints indices are winsorized at the first and ninety-ninth percentile.

Other variables that appear in the paper are: Age, which is the number of years since the

\footnotetext{
${ }^{34}$ The constant in the Whited-Wu index has been kindly provided by Toni Whited.
} 
company first appeared in the CRSP monthly file; Rating, a dummy variable equaling one if the firm's debt is rated according to item 280; Analysts, which is the average number of analysts following the firm in a given year according to IBES data (if the firm does not appear in the data set for a given year the variable is set to zero); Capital Expenditures (CAPEX), item 128, is normalized by total assets in the previous period; Research and Development, item 46, is normalized by total assets in the previous period. 


\section{References}

Almeida, H., Campello, M., Weisbach, M., 2004. The cash flow sensitivity of cash. Journal of Finance 59, 1777-1804.

Alti, A., 2003. How sensitive is investment to cash flow when financing is frictionless? Journal of Finance 58, 707-722.

Angrist, J., Lavy, V., 1999. Using Maimonides' rule to estimate the effect of class size on student achievement. Quarterly Journal of Economics 114, 533-575.

Bebchuck, L., Cohen, A., 2005. The costs of entrenched boards. Journal of Financial Economics $78,409-433$.

Bebchuck, L., Cohen, A., Ferrell, A., 2004. What matters in corporate governance? Working paper. Harvard University.

Bergstresser, D., Desai, M., Rauh, J., 2006. Earnings manipulation, pension assumptions and managerial investment decisions. Quarterly Journal of Economics 121, 157-195.

Bertrand, M., Mullainathan, S., 2003. Enjoying the quiet life: corporate governance and managerial preferences. Journal of Political Economy 111, 1043-1075.

Blanchard, O., Lopez-de-Silanes, F., Shleifer, A., 1994. What do firms do with cash windfalls? Journal of Financial Economics 36, 337-360.

Chan, K., Chan, L., Jegadeesh, N., Lakonishok, J., 2006. Earnings quality and stock returns. Journal of Business 79, 1041-1082.

Chaney, T., Sraer, D., Thesmar, D., 2007. The corporate wealth effect: from real estate shocks to corporate investment. Working paper. University of Chicago and HEC School of Management, Paris.

Cleary, S., 1999. The relationship between firm investment and financial status. Journal of Finance $54,673-692$. 
Coronado, J. L., Sharpe, S., 2003. Did pension plan accounting contribute to a stock market bubble? Brookings Papers on Economic Activity 1, 323-359.

Cremers, M., Nair, V., 2005. Governance mechanisms and equity prices. Journal of Finance 60, $2859-2894$.

Cremers, M., Nair, V., John, K., 2005. Takeovers and the cross-section of returns. Working paper. Yale ICF No. 07-13.

Daniel, K., Grinblatt, M., Titman, S., Wermers, R., 1997. Measuring mutual fund performance with characteristic-based benchmarks. Journal of Finance 52, 1035-1058.

Denis, D., Sibilkov, V., 2007. Financial constraints, investment, and the value of cash holdings. Review of Financial Studies, forthcoming.

Dittmar, A., Mahrt-Smith, J., 2007. Corporate governance and the value of cash holdings. Journal of Financial Economics 83, 599-634.

Erickson, T., Whited, T., 2000. Measurement error and the relationship between investment and q. Journal of Political Economy 108, 1027-1057.

Fama, E., French, K., 1993. Common risk factors in the returns on stocks and bonds. Journal of Financial Economics 33, 3-56.

Fama, E., MacBeth, J., 1973. Risk, return, and equilibrium: Empirical tests. Journal of Political Economy 81, 607-636.

Faulkender, M., Wang, R., 2006. Corporate financial policy and the value of cash. Journal of Finance 61, 1957-1990.

Fazzari, S., Hubbard, G., Petersen, B., 1988. Financing constraints and corporate investment. Brookings Papers on Economic Activity 1, 141-195.

Fazzari, S., Hubbard, G., Petersen, B., 2000. Investment-cash flow sensitivities are useful: A comment on Kaplan-Zingales. Quarterly Journal of Economics 115, 695-705. 
Franzoni, F., Marin, J., 2006a. Pension plan funding and stock market efficiency. Journal of Finance $61,921-956$.

Franzoni, F., Marin, J., 2006b. Portable alphas from pension mispricing. Journal of Portfolio Management Summer, 44-53.

Frésard, L., Salva, C., 2007. Does cross-listing in the U.S really improve corporate governance? Evidence from the value of corporate liquidity. Working paper. HEC School of Management, Paris.

Gomes, J., 2001. Financing investment. American Economic Review 91, 767-788.

Gomes, J., Yaron, A., Zhang, L., 2006. Asset pricing implications of firms' financing constraints. Review of Financial Studies 19, 1321-1356.

Gompers, P., Ishii, J., Metrick, A., 2003. Corporate governance and equity prices. Quarterly Journal of Economics 118, 107-155.

Graham, J., Harvey, C., Rajgopal, S., 2005. The economic implications of corporate financial reporting. Journal of Accounting and Economics 40, 3-73.

Greenwald, B., Stiglitz, J., Weiss, A., 1984. Informational imperfections in the capital market and macroeconomic fluctuations. American Economic Review 74, 194-199.

Grossman, S., Hart, O., 1982. Corporate financial structure and managerial incentives. In: McCall, J. (Ed.), The Economics of Information and Uncertainty. University of Chicago Press, Chicago, pp. 107-140.

Hart, O., Moore, J., 1995. Debt and seniority: An analysis of the role of hard claims in constraining management. American Economic Review 85, 567-585.

Hennessy, C., Whited, T., 2007. How costly is external financing? Evidence from a structural estimation. Journal of Finance 62, 1705-1745. 
Hong, H., Lim, T., Stein, J., 2000. Bad news travels slowly: Size, analyst coverage, and the profitability of momentum strategies. Journal of Finance 55, 265-295.

Hubbard, G., 1998. Capital-market imperfections and investment. The Review of Economics and Statistics 36, 193-225.

Jensen, M., 1986. Agency costs of free cash flow, corporate finance, and takeovers. American Economic Review 76, 323-329.

Jensen, M., Meckling, W., 1976. Theory of the firm: Managerial behavior, agency costs and ownership structure. Journal of Financial Economics 3, 305-360.

Kaplan, S., Zingales, L., 1997. Do investment-cash flow sensitivities provide useful measures of financing constraints? Quarterly Journal of Economics 112, 169-215.

Kaplan, S., Zingales, L., 2000. Investment-cash flow sensitivities are not valid measures of financing constraints. Quarterly Journal of Economics 115, 707-712.

Lamont, O., 1997. Cash flow and investment: evidence from internal capital markets. Journal of Finance 52, 83-109.

Lamont, O., Polk, C., Saa-Requejo, J., 2001. Financial constraints and stock returns. Review of Financial Studies 14, 529-554.

Lang, L., Stulz, R., Walkling, R., 1991. A test of the free cash flow hypothesis: The case of bidder returns. Journal of Financial Economics 29, 315-336.

Lewellen, W., Loderer, C., Rosenfeld, A., 1985. Merger decisions and executive stock ownership in acquiring firms. Journal of Accounting and Economics 7, 209-231.

Masulis, R., Wang, C., Xie, F., 2007. Corporate governance and acquirer returns. Journal of Finance, 62, 1851-1889.

McConnell, J., Muscarella, C., 1985. Corporate capital expenditure decisions and the market value of the firm. Journal of Financial Economics 14, 399-422. 
Morck, R., Shleifer, A., Vishny, R., 1990. Do managerial incentives drive bad acquisitions? Journal of Finance 45, 31-48.

Moyen, N., 2004. Investment-cash flow sensitivities: Constrained versus unconstrained firms. Journal of Finance 69, 2061-2092.

Myers, S., Majluf, N., 1984. Corporate financing and investment decisions when firms have information that investors do not have. Journal of Financial Economics 13, 187-221.

Officer, M., 2007. Overinvestment, corporate governance, and dividend initiations. Working paper. University of Southern California.

Perez-Quiros, G., Timmermann, A., 2000. Firm size and cyclical variations in stock returns. Journal of Finance 55, 1229-1262.

Pinkowitz, L., Stulz, R., Williamson, R., 2006. Does the contribution of corporate cash holdings and dividends to firm value depend on governance? A cross-country analysis. Journal of Finance $61,2725-2751$.

Pinkowitz, L., Williamson, R., 2004. What is a dollar worth? The market value of cash holdings. Working paper. Georgetown University.

Rauh, J., 2006. Investment and financing constraints: Evidence from the funding of corporate pension plans. Journal of Finance 61, 33-72.

Shleifer, A., Vishny, R., 1986. Large shareholders and corporate control. Journal of Political Economy $94,461-488$.

Stein, J., 2003. Agency, information and corporate investment. In: Constantinides, G., Harris, M., Stulz, R. (Eds.), Handbook of the Economics of Finance. Elsevier Science B.V., Ch. 2.

Stulz, R., 1990. Managerial discretion and optimal financing policies. Journal of Financial Economics $26,3-27$. 
Thompson, S., 2006. Simple formulas for standard errors that cluster by both firm and time. Working paper. Harvard University.

Whited, T., Wu, G., 2006. Financial constraints risk. Review of Financial Studies 19, 531-559.

Wooldridge, J., 2002. Econometric analysis of cross section and panel data, 1st Edition. MIT Press, Cambridge, MA. 


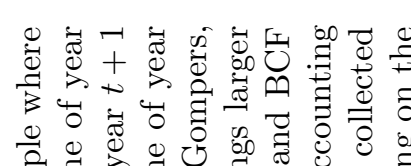

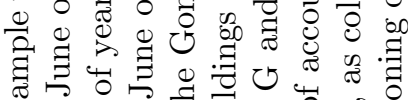

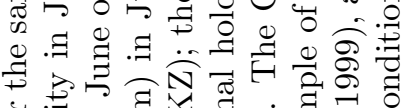

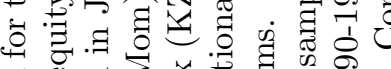

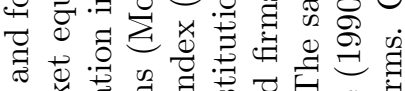

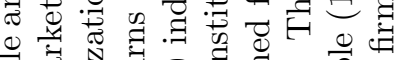

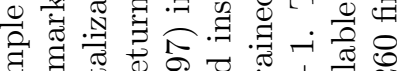

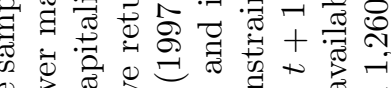

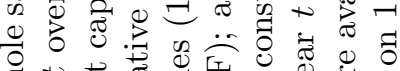

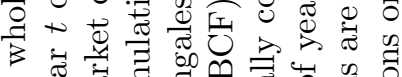
o

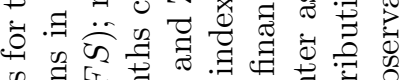
员运言

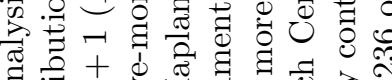
不 을

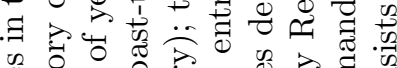

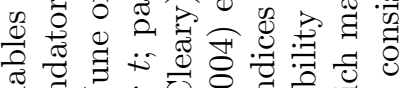

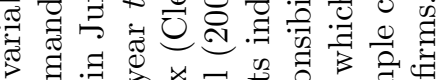

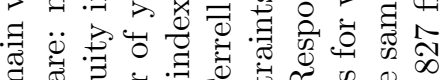

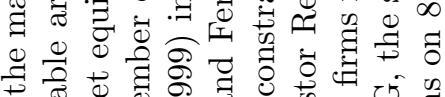

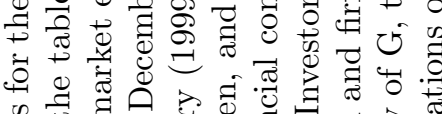

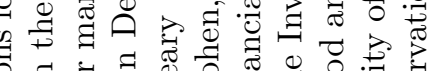

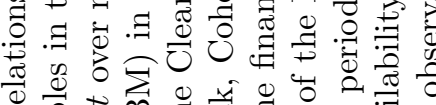

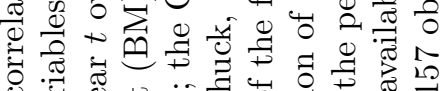
8 告 क्ष

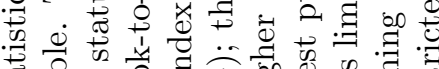

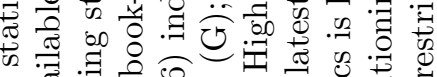

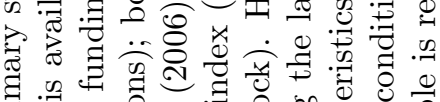

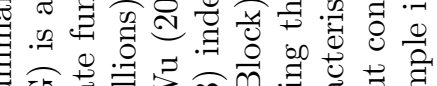

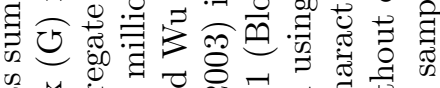

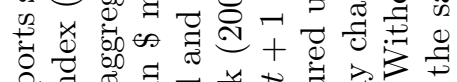

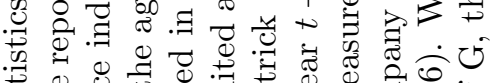

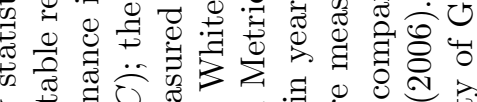

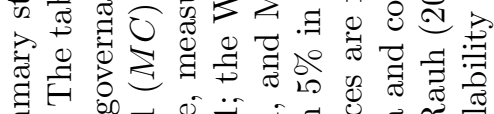

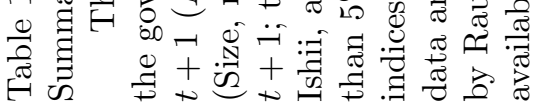

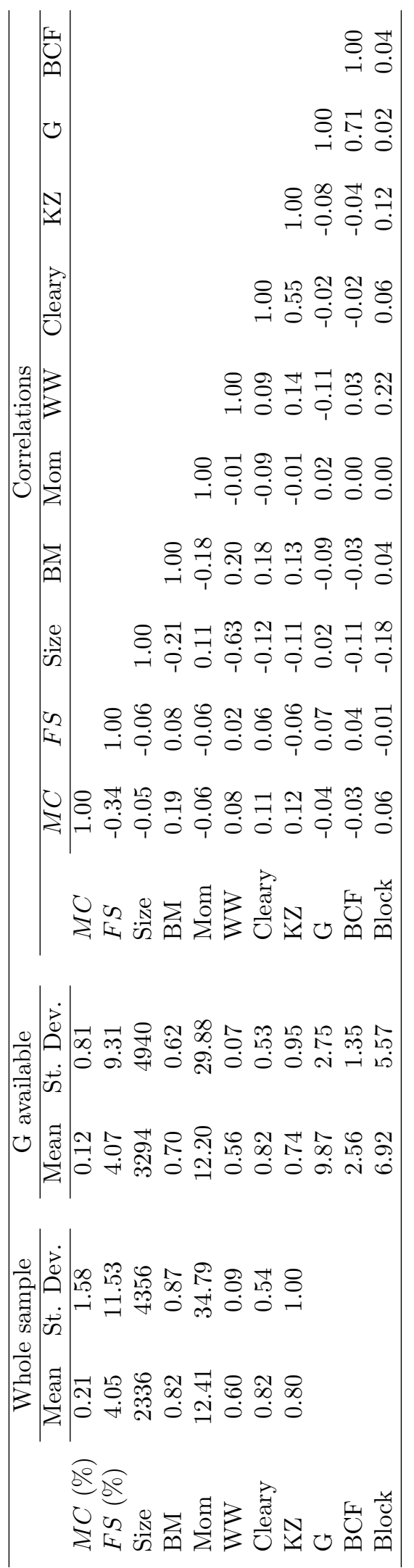


Table 2

Descriptive statistics by $M C$ groups

The table reports sample means and medians of different firm characteristics by levels of mandatory contributions in year $t$ over market equity in June of year $t+1(M C)$. The first two columns use all firm-year observations for which $M C=0$ (4,402 observations). The third and fourth columns use the bottom $50 \%$ of observations for which $M C>0$ (921 observations). The fifth and sixth columns use the top $50 \%$ of observations for which $M C>0$ (913 observations). The median of $M C$, conditioning on $M C>0$, is about $0.09 \%$. The firm characteristics are: $M C$ in $\%$, the funding status over equity $(F S$, in \%), the financial constraints indices (WW, Cleary, KZ), the governance index $(\mathrm{G})$, the entrenchment index (BCF), the percentage of blockholdings (Block), market capitalization in June of year $t+1$ (Size, in \$ millions), book-to-market (BM), firm's age, a dummy for firms whose bonds are rated, the average number of analysts following the firm in the 12 months up to June of year $t+1$, cash flows over assets (CF), total long-term debt over assets (TLTD), total dividends over assets (TDIV), a dummy that equals one if the firm pays dividends (DIVPOS), total cash over assets (CASH), capital expenditures over assets (CAPEX), research and development expenses over assets $(\mathrm{RD})$, the firm's real sales growth in year $t(\mathrm{SG})$, the coverage ratio for interests and preferred dividends (COVER), the ratio of net income to net sales (IMARG), a measure of financial slack (SLACK). See the text and the appendix for the details on variable definitions. The sample of accounting data and company characteristics is limited to the period and firms for which mandatory contributions are available (1990-1999), as collected by Rauh (2006). Without conditioning on the availability of G, the sample consists of 6,236 observations on 1,260 firms. Conditioning on the availability of G, the sample is restricted to 4,157 observations on 827 firms.

\begin{tabular}{|c|c|c|c|c|c|c|}
\hline \multirow[b]{4}{*}{$M C(\%)$} & & & \multicolumn{4}{|c|}{$M C>0$} \\
\hline & \multicolumn{2}{|c|}{$M C=0$} & \multicolumn{2}{|c|}{ Bottom $50 \%$} & \multicolumn{2}{|c|}{ Top $50 \%$} \\
\hline & Mean & Median & Mean & Median & Mean & Median \\
\hline & 0.000 & 0.000 & 0.032 & 0.021 & 1.369 & 0.449 \\
\hline$F S(\%)$ & 5.661 & 2.098 & 2.638 & 0.443 & -2.269 & -1.003 \\
\hline WW & 0.596 & 0.594 & 0.574 & 0.571 & 0.639 & 0.642 \\
\hline $\mathrm{KZ}$ & 0.706 & 0.725 & 0.770 & 0.799 & 1.264 & 1.259 \\
\hline Cleary & 0.789 & 0.800 & 0.779 & 0.785 & 1.028 & 1.024 \\
\hline G & 9.864 & 10.000 & 9.942 & 10.000 & 9.829 & 10.000 \\
\hline $\mathrm{BCF}$ & 2.542 & 3.000 & 2.531 & 3.000 & 2.525 & 3.000 \\
\hline Block & 6.564 & 6.740 & 7.196 & 7.498 & 7.951 & 8.330 \\
\hline Size & 2401 & 655 & 3385 & 1126 & 968 & 176 \\
\hline BM & 0.809 & 0.658 & 0.618 & 0.525 & 1.096 & 0.833 \\
\hline Age & 27.619 & 25.000 & 28.293 & 25.000 & 24.330 & 22.000 \\
\hline Rating & 0.477 & 0.000 & 0.594 & 1.000 & 0.400 & 0.000 \\
\hline Analysts & 7.791 & 4.250 & 9.769 & 7.592 & 4.984 & 2.083 \\
\hline $\mathrm{CF}$ & 0.094 & 0.093 & 0.099 & 0.099 & 0.069 & 0.075 \\
\hline TLTD & 0.382 & 0.405 & 0.384 & 0.387 & 0.461 & 0.460 \\
\hline TDIV & 0.019 & 0.017 & 0.018 & 0.017 & 0.010 & 0.006 \\
\hline DIVPOS & 0.818 & 1.000 & 0.818 & 1.000 & 0.657 & 1.000 \\
\hline CASH & 0.062 & 0.027 & 0.059 & 0.028 & 0.055 & 0.026 \\
\hline CAPEX & 0.078 & 0.065 & 0.075 & 0.063 & 0.064 & 0.054 \\
\hline $\mathrm{RD}$ & 0.033 & 0.018 & 0.031 & 0.021 & 0.024 & 0.014 \\
\hline $\mathrm{SG}$ & 0.044 & 0.028 & 0.051 & 0.030 & 0.029 & 0.019 \\
\hline COVER & 12.957 & 3.991 & 11.510 & 4.637 & 7.673 & 2.577 \\
\hline IMARG & 0.049 & 0.047 & 0.047 & 0.044 & 0.016 & 0.024 \\
\hline SLACK & 0.241 & 0.001 & 0.161 & 0.014 & 0.177 & 0.044 \\
\hline
\end{tabular}


Table 3

Return reactions to mandatory contributions

The table reports estimates from OLS regressions of annual returns between July of year $t+1$ and June of year $t+2$ (in \%) on the amount of mandatory contributions in year $t$ over market equity in June of year $t+1(M C$, in \%). The other columns of each panel also control for the funding status by including: the aggregate funding status over assets ( $F S$, second column), separate controls for under- and overfunding over equity (third column), and the first three powers of under- and overfunding (fourth column, squares and cubes not shown). In each specification, additional control variables are: year fixed effects, book-to-market $(\mathrm{BM})$, size, past-12-months returns (Mom), and a set of industry dummies computed using three-digit SIC codes. The controls are interacted with year fixed effects and they are measured in December of year $t$, except for size and Mom that are computed in June of year $t+1$. In Panel A, the dependent variable is the raw return. In Panel $\mathrm{B}$, the dependent variable is the abnormal return relative to ten beta-matching portfolios. In Panel $\mathrm{C}$, the dependent variable is the abnormal return relative to 17 industry-matching portfolios (Prof. Ken French's data). In Panel D, the dependent variable is the abnormal return relative to 125 size-BM-momentum-matching portfolios. Annual returns range between July of 1991 and June of 2001. The sample consists of 6,236 observations on 1,260 firms. Standard errors are clustered by firm and year according to the procedure in Thompson (2006). T-statistics are reported in parentheses.

\begin{tabular}{|c|c|c|c|c|c|c|c|c|c|}
\hline \multicolumn{5}{|c|}{ Panel A: Raw returns } & \multicolumn{5}{|c|}{ Panel B: Beta adjusted } \\
\hline$M C$ & $\begin{array}{c}-1.14 \\
(-5.00)\end{array}$ & $\begin{array}{l}-1.12 \\
(-4.73)\end{array}$ & $\begin{array}{c}-0.98 \\
(-2.23)\end{array}$ & $\begin{array}{l}-1.50 \\
(-2.35)\end{array}$ & $M C$ & $\begin{array}{c}-0.84 \\
(-4.60)\end{array}$ & $\begin{array}{c}-0.76 \\
(-4.53)\end{array}$ & $\begin{array}{c}-0.89 \\
(-2.60)\end{array}$ & $\begin{array}{l}-1.51 \\
(-3.17)\end{array}$ \\
\hline$F S$ & & $\begin{array}{c}0.01 \\
(0.12)\end{array}$ & & & $F S$ & & $\begin{array}{c}0.03 \\
(1.03)\end{array}$ & & \\
\hline Over & & & $\begin{array}{c}-0.07 \\
(-0.43)\end{array}$ & $\begin{array}{c}0.38 \\
(0.81)\end{array}$ & Over & & & $\begin{array}{c}0.03 \\
(0.25)\end{array}$ & $\begin{array}{c}0.43 \\
(0.96)\end{array}$ \\
\hline Under & & & $\begin{array}{l}-0.00 \\
(-0.04)\end{array}$ & $\begin{array}{c}0.23 \\
(1.64)\end{array}$ & Under & & & $\begin{array}{c}0.04 \\
(1.11)\end{array}$ & $\begin{array}{c}0.36 \\
(3.29)\end{array}$ \\
\hline Powers & 0 & 1 & 1 & $1,2,3$ & Powers & 0 & 1 & 1 & $1,2,3$ \\
\hline \multicolumn{5}{|c|}{ Panel C: Industry adjusted } & \multicolumn{5}{|c|}{ Panel D: Size-BM-Mom adjusted } \\
\hline$M C$ & $\begin{array}{c}-0.90 \\
(-3.95)\end{array}$ & $\begin{array}{l}-0.92 \\
(-4.43)\end{array}$ & $\begin{array}{l}-1.04 \\
(-2.92)\end{array}$ & $\begin{array}{c}-1.44 \\
(-2.51)\end{array}$ & $M C$ & $\begin{array}{l}-0.70 \\
(-3.30)\end{array}$ & $\begin{array}{c}-0.78 \\
(-3.54)\end{array}$ & $\begin{array}{l}-0.46 \\
(-1.23)\end{array}$ & $\begin{array}{c}-1.00 \\
(-1.71)\end{array}$ \\
\hline$F S$ & & $\begin{array}{c}-0.01 \\
(-0.16)\end{array}$ & & & $F S$ & & $\begin{array}{c}-0.03 \\
(-0.75)\end{array}$ & & \\
\hline Over & & & $\begin{array}{c}0.06 \\
(0.48)\end{array}$ & $\begin{array}{c}0.09 \\
(0.18)\end{array}$ & Over & & & $\begin{array}{c}-0.12 \\
(-0.74)\end{array}$ & $\begin{array}{c}0.18 \\
(0.41)\end{array}$ \\
\hline Under & & & $\begin{array}{c}0.00 \\
(0.03)\end{array}$ & $\begin{array}{c}0.20 \\
(1.16)\end{array}$ & Under & & & $\begin{array}{c}-0.05 \\
(-1.38)\end{array}$ & $\begin{array}{c}0.18 \\
(1.28)\end{array}$ \\
\hline Powers & 0 & 1 & 1 & $1,2,3$ & Powers & 0 & 1 & 1 & $1,2,3$ \\
\hline
\end{tabular}


Table 4

Return reactions and financial constraints

The table reports estimates from OLS regressions of annual returns between July of year $t+1$ and June of year $t+2$ (in \%) on the amount of mandatory contributions in year $t$ over market equity in June of year $t+1(M C$, in \%), an index of financial constraints (FC), and the interactions between $M C$ and a dummy variable that denotes firms classified into the high (top 25\%) group of the financial constraints index for year t. Additional controls are: year fixed effects, book-to-market (BM), size, past-12-months returns (Mom), and a set of industry dummies computed using three-digit SIC codes. The controls are interacted with year fixed effects. All of the control variables are measured in December of year $t$, except for size and Mom that are computed in June of year $t+1$. The financial constraints indices are: the Whited and Wu (2006) index, the Cleary (1999) index, and the Kaplan and Zingales (1997) index. Higher levels of the financial constraints indices denote more financially constrained firms. The three indices have been standardized. In Panel A, the dependent variable is the raw return. In Panel B, the dependent variable is the abnormal return relative to ten beta-matching portfolios. In Panel $\mathrm{C}$, the dependent variable is the abnormal return relative to 17 industry-matching portfolios (Prof. Ken French's data). In Panel D, the dependent variable is the abnormal return relative to 125 size-BM-momentum-matching portfolios. Annual returns range between July of 1991 and June of 2001. The sample consists of 6,236 observations on 1,260 firms. Standard errors are clustered by firm and year according to the procedure in Thompson (2006). T-statistics are reported in parentheses.

\begin{tabular}{|c|c|c|c|c|c|c|c|}
\hline \multicolumn{4}{|c|}{ Panel A: Raw returns } & \multicolumn{4}{|c|}{ Panel B: Beta adjusted } \\
\hline \multirow{3}{*}{$M C$} & WW & Cleary & KZ & \multirow{3}{*}{$M C$} & WW & Cleary & KZ \\
\hline & -0.65 & 0.06 & 0.19 & & -0.24 & 0.36 & 0.78 \\
\hline & $(-2.51)$ & $(0.31)$ & $(0.51)$ & & $(-1.07)$ & $(0.83)$ & $(1.50)$ \\
\hline \multirow[t]{2}{*}{ FC Index } & 2.79 & -0.15 & -0.08 & \multirow[t]{2}{*}{ FC Index } & 3.48 & 0.04 & -1.00 \\
\hline & $(1.23)$ & $(-0.12)$ & $(-0.12)$ & & $(1.57)$ & $(0.03)$ & $(-0.98)$ \\
\hline \multirow[t]{2}{*}{$\mathrm{Hi} \mathrm{FC} \times M C$} & -1.49 & -1.28 & -1.38 & \multirow[t]{2}{*}{$\mathrm{Hi} \mathrm{FC} \times M C$} & -1.66 & -1.24 & -1.62 \\
\hline & $(-3.24)$ & $(-3.69)$ & $(-2.92)$ & & $(-9.43)$ & $(-2.95)$ & $(-3.35)$ \\
\hline \multicolumn{4}{|c|}{ Panel C: Industry adjusted } & \multicolumn{4}{|c|}{ Panel D: Size-BM-Mom adjusted } \\
\hline \multirow{3}{*}{$M C$} & WW & Cleary & $\mathrm{KZ}$ & \multirow{3}{*}{$M C$} & WW & Cleary & KZ \\
\hline & -0.50 & -0.05 & 0.23 & & -0.28 & 0.20 & -0.05 \\
\hline & $(-2.29)$ & $(-0.74)$ & $(0.96)$ & & $(-1.15)$ & $(0.73)$ & $(-0.17)$ \\
\hline \multirow[t]{2}{*}{ FC Index } & 2.60 & -0.03 & -0.54 & \multirow[t]{2}{*}{ FC Index } & -0.01 & -0.21 & 0.06 \\
\hline & $(1.11)$ & $(-0.02)$ & $(-0.57)$ & & $(-0.01)$ & $(-0.20)$ & $(0.06)$ \\
\hline \multirow[t]{2}{*}{$\mathrm{Hi} \mathrm{FC} \times M C$} & -1.36 & -0.94 & -1.22 & \multirow[t]{2}{*}{$\mathrm{Hi} \mathrm{FC} \times M C$} & -1.60 & -1.05 & -0.78 \\
\hline & $(-2.72)$ & $(-3.09)$ & $(-3.68)$ & & $(-3.94)$ & $(-2.74)$ & $(-2.82)$ \\
\hline
\end{tabular}


Table 5

Return reactions and corporate governance index

The table reports estimates from OLS regressions of annual returns between July of year $t+1$ and June of year $t+2$ (in \%) on the amount of mandatory contributions in year $t$ over market equity in June of year $t+1(M C$, in \%), two dummy variables for firms in the medium and top terciles of the distribution of Gompers, Ishii, and Metrick (2003) index of corporate governance (G), and the interaction between these dummies and $M C$. Only the slopes involving High $\mathrm{G}$ (poorly governed) firms are reported. Additional control variables are: year fixed effects, book-to-market (BM), size, past-12-months returns (Mom), and a set of industry dummies computed using three-digit SIC codes. The controls are interacted with year fixed effects. All of the control variables are measured in December of year $t$, except for size and Mom that are computed in June of year $t+1$. The first column of each panel excludes the $\mathrm{G}$ index dummies from the regression. In each panel, the models in the third, fourth, and fifth columns also include: an index of financial constraints, and the interactions between mandatory contributions and a dummy variable that denotes firms classified into the high (top 25\%) group of the financial constraints index for year $t$. The financial constraints indices are: the Whited and Wu (2006) index, the Cleary (1999) index, and the Kaplan and Zingales (1997) index. Higher levels of the financial constraints indices denote more financially constrained firms. The three indices have been standardized. The $\mathrm{G}$ index is measured using the latest publication of the Investor Responsibility Research Center as of year $t+1$. In Panel $\mathrm{A}$, the dependent variable is the raw return. In Panel B, the dependent variable is the abnormal return relative to ten beta-matching portfolios. In Panel C, the dependent variable is the abnormal return relative to 17 industry-matching portfolios (Prof. Ken French's data). In Panel D, the dependent variable is the abnormal return relative to 125 size-BMmomentum-matching portfolios. Annual returns range between July of 1991 and June of 2001. The sample consists of 4,157 observations on 827 firms. Standard errors are clustered by firm and year according to the procedure in Thompson (2006). T-statistics are reported in parentheses.

\begin{tabular}{|c|c|c|c|c|c|c|c|c|c|c|c|}
\hline \multicolumn{6}{|c|}{ Panel A: Raw returns } & \multicolumn{6}{|c|}{ Panel B: Beta adjusted } \\
\hline & & & WW & Cleary & KZ & & & & WW & Cleary & KZ \\
\hline \multirow[t]{2}{*}{$M C$} & -1.14 & -1.90 & -1.39 & -1.76 & -1.40 & $M C$ & -0.75 & -1.36 & -0.87 & -1.78 & -1.27 \\
\hline & $(-2.04)$ & $(-2.01)$ & $(-2.03)$ & $(-2.15)$ & $(-1.85)$ & & $(-1.35)$ & $(-1.46)$ & $(-1.33)$ & $(-2.35)$ & $(-1.92)$ \\
\hline \multirow[t]{2}{*}{ High G } & & 1.00 & 1.51 & 1.29 & 1.25 & High G & & 0.75 & 1.24 & 0.96 & 0.96 \\
\hline & & $(0.21)$ & $(0.34)$ & $(0.27)$ & $(0.26)$ & & & $(0.15)$ & $(0.26)$ & $(0.19)$ & $(0.19)$ \\
\hline \multirow[t]{2}{*}{$M C \times \mathrm{Hi} \mathrm{G}$} & & 5.30 & 4.60 & 5.11 & 5.51 & $M C \times \mathrm{Hi} \mathrm{G}$ & & 3.87 & 3.16 & 3.60 & 4.03 \\
\hline & & $(3.80)$ & $(3.11)$ & $(2.97)$ & $(4.95)$ & & & $(2.48)$ & $(2.03)$ & $(1.92)$ & $(3.05)$ \\
\hline \multirow[t]{2}{*}{$M C \times \mathrm{Hi} \mathrm{FC}$} & & & -5.25 & -0.30 & -0.73 & $M C \times \mathrm{Hi} \mathrm{FC}$ & & & -5.08 & 0.56 & -0.13 \\
\hline & & & $(-2.22)$ & $(-0.23)$ & $(-1.02)$ & & & & $(-2.02)$ & $(0.41)$ & $(-0.14)$ \\
\hline \multicolumn{6}{|c|}{ Panel C: Industry adjusted } & \multicolumn{6}{|c|}{ Panel D: Size-BM-Mom adjusted } \\
\hline \multirow{3}{*}{$M C$} & & & WW & Cleary & KZ & & & & WW & Cleary & KZ \\
\hline & -0.60 & -1.21 & -0.71 & -1.39 & -0.70 & $M C$ & -0.90 & -1.56 & -0.92 & -1.41 & -1.15 \\
\hline & $(-1.37)$ & $(-1.64)$ & $(-1.69)$ & $(-1.97)$ & $(-1.54)$ & & $(-1.42)$ & $(-1.59)$ & $(-1.72)$ & $(-2.26)$ & $(-1.88)$ \\
\hline \multirow[t]{2}{*}{ High G } & & 3.63 & 3.73 & 3.94 & 3.90 & High G & & 2.56 & 2.73 & 2.94 & 2.76 \\
\hline & & $(0.91)$ & $(0.99)$ & $(1.02)$ & $(0.96)$ & & & $(0.57)$ & $(0.63)$ & $(0.67)$ & $(0.60)$ \\
\hline \multirow[t]{2}{*}{$M C \times \mathrm{Hi} \mathrm{G}$} & & 4.29 & 3.61 & 4.15 & 4.56 & $M C \times \mathrm{Hi} \mathrm{G}$ & & 5.37 & 4.67 & 5.15 & 5.57 \\
\hline & & $(2.61)$ & $(2.04)$ & $(2.17)$ & $(3.32)$ & & & $(3.44)$ & $(2.70)$ & $(2.65)$ & $(4.49)$ \\
\hline \multirow[t]{2}{*}{$M C \times \mathrm{Hi} \mathrm{FC}$} & & & -5.23 & 0.16 & -0.78 & $M C \times \mathrm{Hi} \mathrm{FC}$ & & & -6.44 & -0.30 & -0.58 \\
\hline & & & $(-1.99)$ & $(0.48)$ & $(-0.83)$ & & & & $(-2.35)$ & $(-0.37)$ & $(-0.45)$ \\
\hline
\end{tabular}


Table 6

Return reactions and entrenchment index

The table reports estimates from OLS regressions of annual returns between July of year $t+1$ and June of year $t+2$ (in \%) on the amount of mandatory contributions in year $t$ over market equity in June of year $t+1(M C$, in \%), the Bebchuck, Cohen, and Ferrell (2004) index of managerial entrenchment (BCF), and the interaction between $\mathrm{BCF}$ and $M C$. Additional control variables are: year fixed effects, book-to-market (BM), size, past-12-months returns (Mom), and a set of industry dummies computed using three-digit SIC codes. The controls are interacted with year fixed effects. All of the control variables are measured in December of year $t$, except for size and Mom that are computed in June of year $t+1$. In each panel, the models in the second, third, and fourth columns also include: an index of financial constraints, and the interactions between mandatory contributions and a dummy variable that denotes firms classified into the high (top 25\%) group of the financial constraints index for year $t$. The financial constraints indices are: the Whited and Wu (2006) index, the Cleary (1999) index, and the Kaplan and Zingales (1997) index. Higher levels of the financial constraints indices denote more financially constrained firms. The three indices have been standardized. The BCF index is measured using the latest publication of the Investor Responsibility Research Center as of year $t+1$. In Panel $\mathrm{A}$, the dependent variable is the raw return. In Panel $\mathrm{B}$, the dependent variable is the abnormal return relative to ten beta-matching portfolios. In Panel $\mathrm{C}$, the dependent variable is the abnormal return relative to 17 industry-matching portfolios (Prof. Ken French's data). In Panel D, the dependent variable is the abnormal return relative to 125 size-BM-momentum-matching portfolios. Annual returns range between July of 1991 and June of 2001. The sample consists of 4,213 observations on 838 firms. Standard errors are clustered by firm and year according to the procedure in Thompson (2006). T-statistics are reported in parentheses.

\begin{tabular}{|c|c|c|c|c|c|c|c|c|c|}
\hline \multicolumn{5}{|c|}{ Panel A: Raw returns } & \multicolumn{5}{|c|}{ Panel B: Beta adjusted } \\
\hline \multirow{3}{*}{$M C$} & & WW & Cleary & KZ & \multirow{3}{*}{$M C$} & & WW & Cleary & KZ \\
\hline & -5.38 & -4.77 & -5.25 & -5.04 & & -4.46 & -3.88 & -4.67 & -4.56 \\
\hline & $(-2.67)$ & $(-2.37)$ & $(-2.69)$ & $(-2.05)$ & & $(-2.10)$ & $(-1.85)$ & $(-2.25)$ & $(-1.77)$ \\
\hline \multirow[t]{2}{*}{$\mathrm{BCF}$} & -0.20 & -0.12 & 0.01 & 0.04 & \multirow[t]{2}{*}{$\mathrm{BCF}$} & -0.04 & 0.04 & 0.18 & 0.19 \\
\hline & $(-0.24)$ & $(-0.16)$ & $(0.01)$ & $(0.05)$ & & $(-0.05)$ & $(0.05)$ & $(0.22)$ & $(0.24)$ \\
\hline \multirow[t]{2}{*}{$M C \times \mathrm{BCF}$} & 2.45 & 2.32 & 2.07 & 2.30 & \multirow[t]{2}{*}{$M C \times \mathrm{BCF}$} & 2.18 & 2.06 & 1.71 & 2.08 \\
\hline & $(2.26)$ & $(2.23)$ & $(2.08)$ & $(2.13)$ & & $(1.87)$ & $(1.81)$ & $(1.64)$ & $(1.78)$ \\
\hline \multirow{2}{*}{\multicolumn{2}{|c|}{$M C \times \mathrm{Hi} \mathrm{FC}$}} & -2.96 & -0.25 & -0.82 & \multirow{2}{*}{\multicolumn{2}{|c|}{$M C \times \mathrm{Hi} \mathrm{FC}$}} & -2.81 & 0.58 & -0.21 \\
\hline & & $(-1.35)$ & $(-0.53)$ & $(-0.72)$ & & & $(-1.19)$ & $(1.61)$ & $(-0.18)$ \\
\hline \multicolumn{5}{|c|}{ Panel C: Industry adjusted } & \multicolumn{5}{|c|}{ Panel D: Size-BM-Mom adjusted } \\
\hline \multirow{3}{*}{$M C$} & & WW & Cleary & $\mathrm{KZ}$ & \multirow{3}{*}{$M C$} & & WW & Cleary & $\mathrm{KZ}$ \\
\hline & -4.63 & -3.97 & -4.53 & -4.16 & & -5.65 & -4.73 & -5.44 & -5.48 \\
\hline & $(-2.32)$ & $(-1.97)$ & $(-2.38)$ & $(-1.74)$ & & $(-2.73)$ & $(-2.38)$ & $(-2.60)$ & $(-2.06)$ \\
\hline \multirow[t]{2}{*}{$\mathrm{BCF}$} & 0.29 & 0.34 & 0.56 & 0.48 & \multirow[t]{2}{*}{$\mathrm{BCF}$} & 0.15 & 0.20 & 0.27 & 0.38 \\
\hline & $(0.38)$ & $(0.46)$ & $(0.71)$ & $(0.66)$ & & $(0.17)$ & $(0.23)$ & $(0.32)$ & $(0.47)$ \\
\hline \multirow[t]{2}{*}{$M C \times \mathrm{BCF}$} & 2.26 & 2.13 & 1.84 & 2.12 & \multirow[t]{2}{*}{$M C \times \mathrm{BCF}$} & 2.61 & 2.42 & 2.25 & 2.48 \\
\hline & $(2.23)$ & $(2.18)$ & (1.91) & $(2.08)$ & & $(2.27)$ & $(2.25)$ & $(2.11)$ & $(2.17)$ \\
\hline \multirow[t]{2}{*}{$M C \times \mathrm{Hi} \mathrm{FC}$} & & -3.22 & 0.17 & -0.87 & \multirow[t]{2}{*}{$M C \times \mathrm{Hi} \mathrm{FC}$} & & -4.47 & -0.20 & -0.56 \\
\hline & & $(-1.38)$ & $(0.25)$ & $(-0.76)$ & & & $(-1.67)$ & $(-0.23)$ & $(-0.36)$ \\
\hline
\end{tabular}


Table 7

Return reactions and blockholdings

The table reports estimates from OLS regressions of annual returns between July of year $t+1$ and June of year $t+2$ (in \%) on the amount of mandatory contributions in year $t$ over market equity in June of year $t+1(M C$, in \%), the percentage of blockholdings (Block), and the interaction between Block and $M C$. Additional control variables are: year fixed effects, book-to-market (BM), size, past-12-months returns (Mom), and a set of industry dummies computed using three-digit SIC codes. The controls are interacted with year fixed effects. All of the control variables are measured in December of year $t$, except for size and Mom that are computed in June of year $t+1$. In each panel, the models in the second, third, and fourth columns also include: an index of financial constraints, and the interactions between mandatory contributions and dummy variables that denote firms classified into the high (top 25\%) and medium (between 25\% and $75 \%$, not reported) groups of the financial constraints index for year $t$. The financial constraints indices are: the Whited and Wu (2006) index, the Cleary (1999) index, and the Kaplan and Zingales (1997) index. Higher levels of the financial constraints indices denote more financially constrained firms. The three indices have been standardized. Blockholdings are institutional ownership shares that are larger than 5\%. They are measured from SEC 13-F filings in year $t+1$. In Panel $\mathrm{A}$, the dependent variable is the raw return. In Panel B, the dependent variable is the abnormal return relative to ten beta-matching portfolios. In Panel C, the dependent variable is the abnormal return relative to 17 industry-matching portfolios (Prof. Ken French's data). In Panel D, the dependent variable is the abnormal return relative to 125 size-BMmomentum-matching portfolios. Annual returns range between July of 1991 and June of 2001. The sample consists of 4,378 observations on 827 firms. Standard errors are clustered by firm and year according to the procedure in Thompson (2006). T-statistics are reported in parentheses.

\begin{tabular}{|c|c|c|c|c|c|c|c|c|c|}
\hline \multicolumn{5}{|c|}{ Panel A: Raw returns } & \multicolumn{5}{|c|}{ Panel B: Beta adjusted } \\
\hline \multirow{3}{*}{$M C$} & & WW & Cleary & KZ & \multirow{3}{*}{$M C$} & & WW & Cleary & KZ \\
\hline & 1.08 & 0.82 & 0.67 & 1.20 & & 0.70 & 0.45 & 0.28 & 0.85 \\
\hline & $(1.81)$ & $(1.30)$ & $(1.02)$ & $(2.22)$ & & $(1.44)$ & $(0.73)$ & $(0.39)$ & $(1.49)$ \\
\hline \multirow[t]{2}{*}{ Block } & -0.18 & -0.25 & -0.20 & -0.23 & \multirow[t]{2}{*}{ Block } & -0.22 & -0.28 & -0.24 & -0.24 \\
\hline & $(-0.67)$ & $(-0.98)$ & $(-0.87)$ & $(-0.75)$ & & $(-0.75)$ & $(-1.01)$ & $(-0.98)$ & $(-0.69)$ \\
\hline \multirow[t]{2}{*}{$M C \times$ Block } & -0.21 & -0.16 & -0.22 & -0.22 & \multirow[t]{2}{*}{$M C \times$ Block } & -0.15 & -0.11 & -0.17 & -0.17 \\
\hline & $(-4.06)$ & $(-2.47)$ & $(-3.34)$ & $(-4.14)$ & & $(-1.40)$ & $(-1.60)$ & $(-6.49)$ & $(-1.54)$ \\
\hline \multirow{2}{*}{\multicolumn{2}{|c|}{$M C \times \mathrm{Hi} \mathrm{FC}$}} & -2.09 & 0.67 & 0.18 & \multirow{2}{*}{\multicolumn{2}{|c|}{$M C \times \mathrm{Hi} \mathrm{FC}$}} & -1.74 & 0.82 & 0.22 \\
\hline & & $(-0.76)$ & $(0.66)$ & $(0.18)$ & & & $(-0.69)$ & $(1.34)$ & $(0.26)$ \\
\hline \multicolumn{5}{|c|}{ Panel C: Industry adjusted } & \multicolumn{5}{|c|}{ Panel D: Size-BM-Mom adjusted } \\
\hline \multirow{3}{*}{$M C$} & & WW & Cleary & $\mathrm{KZ}$ & \multirow{3}{*}{$M C$} & & WW & Cleary & $\mathrm{KZ}$ \\
\hline & 1.54 & 1.32 & 0.86 & 1.61 & & 1.28 & 1.02 & 0.80 & 1.19 \\
\hline & $(3.99)$ & $(2.61)$ & $(1.78)$ & $(1.19)$ & & $(2.70)$ & $(1.85)$ & $(1.31)$ & $(2.70)$ \\
\hline \multirow[t]{2}{*}{ Block } & -0.21 & -0.26 & -0.24 & -0.26 & \multirow[t]{2}{*}{ Block } & -0.27 & -0.32 & -0.29 & -0.29 \\
\hline & $(-0.80)$ & $(-1.05)$ & $(-1.07)$ & $(-0.81)$ & & $(-1.17)$ & $(-1.41)$ & $(-1.44)$ & $(-1.04)$ \\
\hline \multirow[t]{2}{*}{$M C \times$ Block } & -0.20 & -0.17 & -0.23 & -0.22 & \multirow[t]{2}{*}{$M C \times$ Block } & -0.19 & -0.13 & -0.22 & -0.22 \\
\hline & $(-7.29)$ & $(-4.05)$ & $(-3.94)$ & $(-7.80)$ & & $(-3.98)$ & $(-1.90)$ & $(-3.52)$ & $(-4.24)$ \\
\hline \multirow[t]{2}{*}{$M C \times \mathrm{Hi} \mathrm{FC}$} & & -1.77 & 1.17 & 0.27 & \multirow[t]{2}{*}{$M C \times \mathrm{Hi} \mathrm{FC}$} & & -2.80 & 0.84 & 0.62 \\
\hline & & $(-0.74)$ & (1.33) & $(0.52)$ & & & $(-1.03)$ & (1.08) & $(0.65)$ \\
\hline
\end{tabular}


Table 8

Firm characteristics by levels of the index of price reactions

The table reports means of different variables by three groups of the price reaction index (PR). The groups include firms with low levels of the index (Low, bottom 25\%), medium levels (Med, between 25\% and $75 \%$ ), and high levels (High, top 25\%). Three versions of the index are constructed combining the Gompers, Ishii, and Metrick (2003) index of corporate governance $(\mathrm{G})$ and one of three indices of financial constraints (FC). PR for firm $i$ in year $t$ is: $P R_{i t}=\hat{\beta}_{1}+\hat{\beta}_{2} G_{i t}+\hat{\gamma}_{1} F C_{i t}$. The coefficients $\hat{\beta}_{1}, \hat{\beta}_{2}$, and $\hat{\gamma}_{1}$ refer to Eq. 2 in the text. The financial constraints indices are: the Whited and $\mathrm{Wu}$ (2006) index, the Cleary (1999) index, and the Kaplan and Zingales (1997) index. Higher levels of the financial constraints indices denote more financially constrained firms. The variables for which the mean is reported are: the governance index $(\mathrm{G})$, the entrenchment index (BCF), blockholdings (Block), the financial constraints indices (WW, Cleary, $\mathrm{KZ})$, the funding status over market equity $(F S$, in \%), mandatory contributions over market equity $(M C$, in \%), the annual raw return up to June of year $t+1$ (Mom), market capitalization in June of year $t+1$ (Size, in $\$$ millions), book-to-market (BM), firm's age, a dummy for firms whose bonds are rated, the average number of analysts following the firm in the 12 months up to June of year $t+1$, capital expenditures over assets (CAPEX), research and development expenses over assets, cash flows over assets (CF), total long-term debt over assets (TLTD), total dividends over assets (TDIV), total cash over assets (CASH), Tobin's $q$ in December of year $t$, a dummy that equals one if the firm pays dividends (DIVPOS), the logarithm of total assets (LNTA), the firm's real sales growth in year $t$ (SG), the ratio of current assets to current liabilities (CURAT), the coverage ratio for interests and preferred dividends (COVER), the ratio of net income to net sales (IMARG), and a measure of financial slack (SLACK). See the text and the appendix for the details on variable definitions.

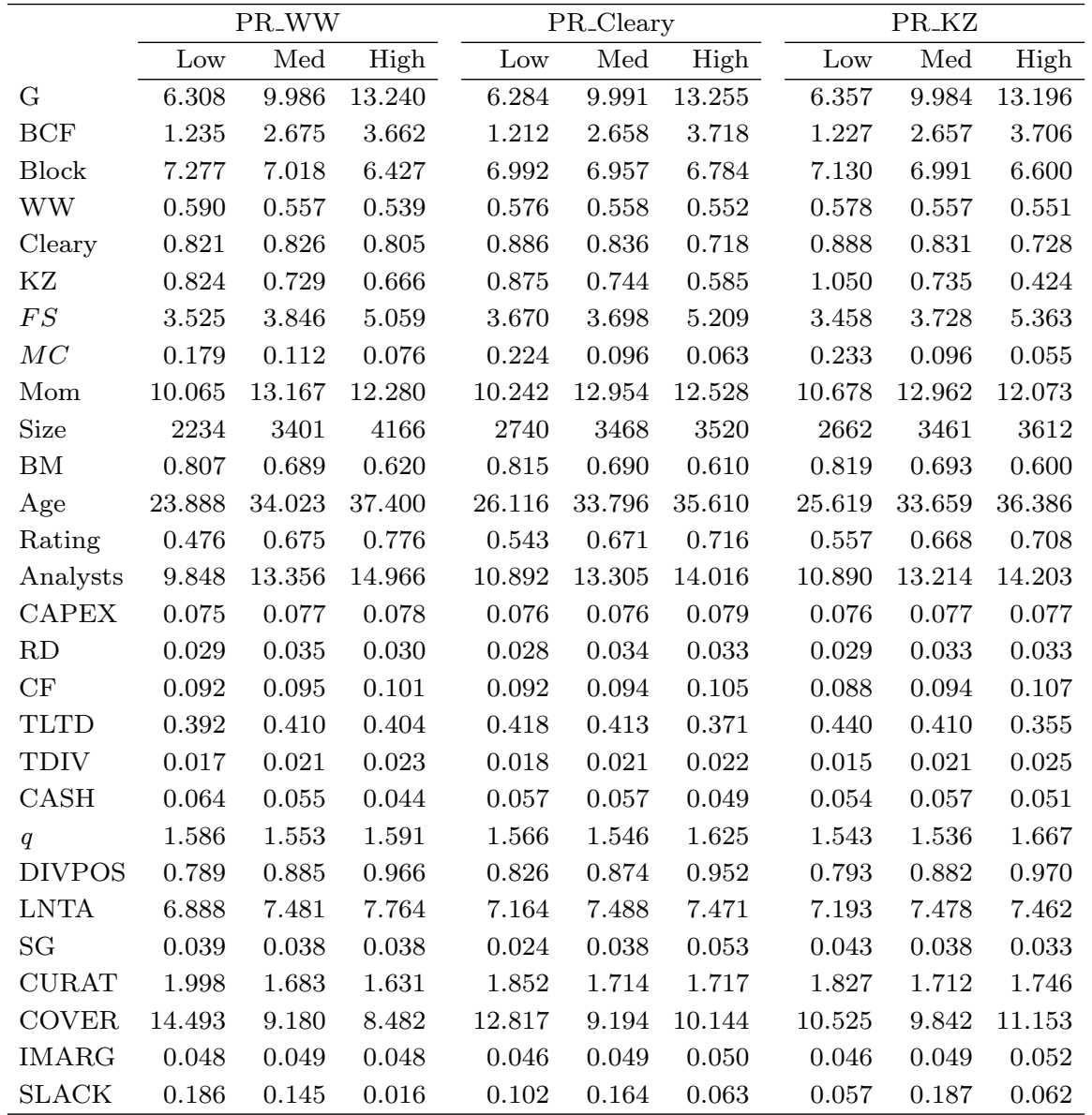




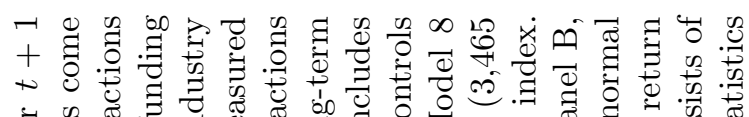
๘ँ

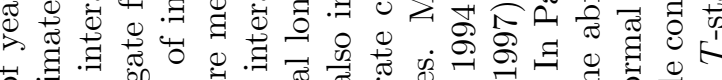

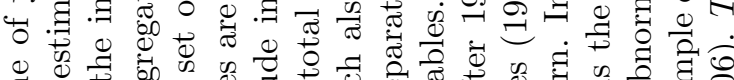

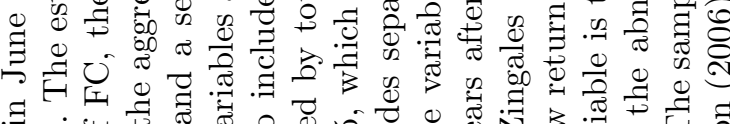

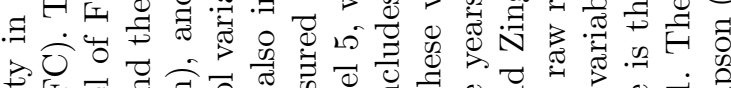

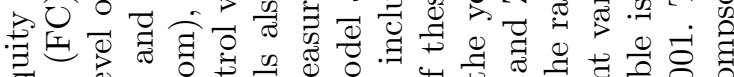

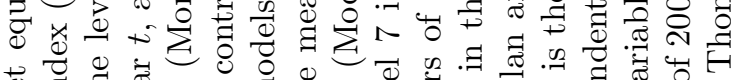

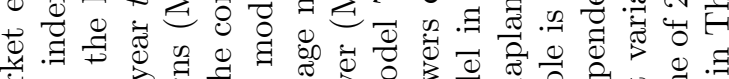

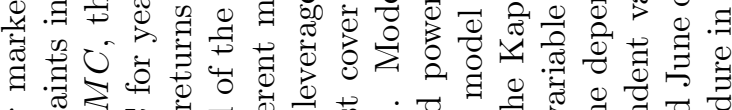

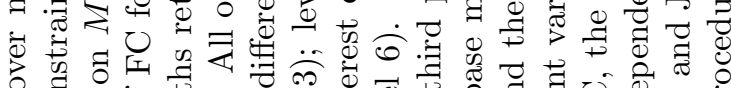

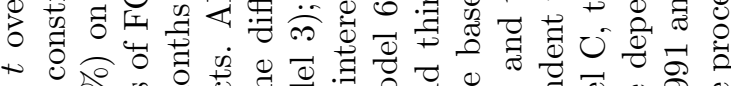

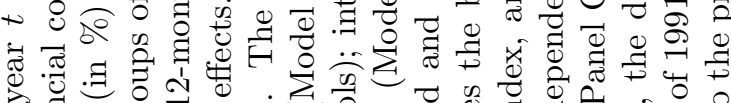

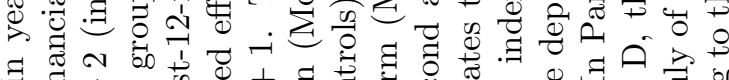

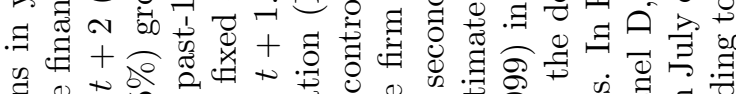
a 0 w 010

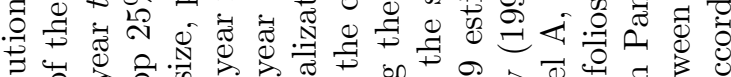

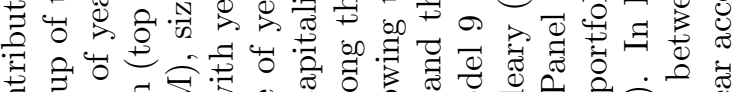

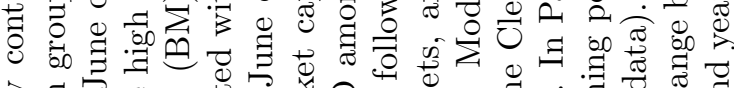
की

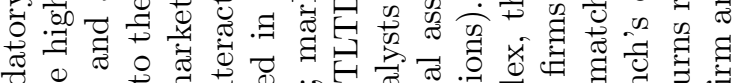

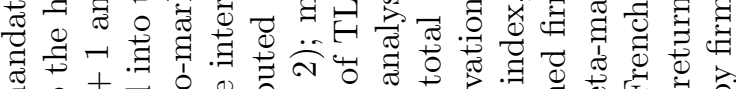
n

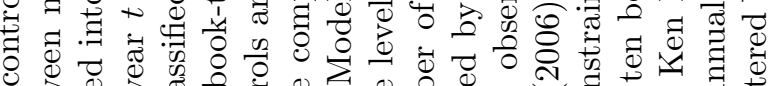

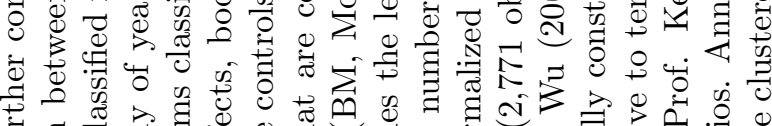

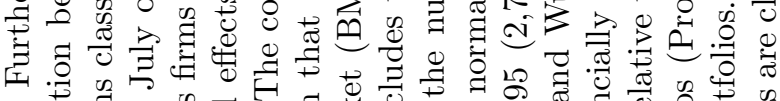

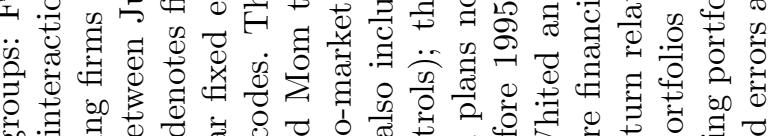
b. . .

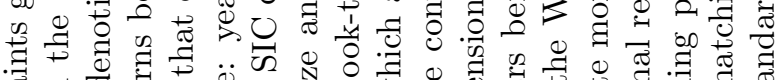

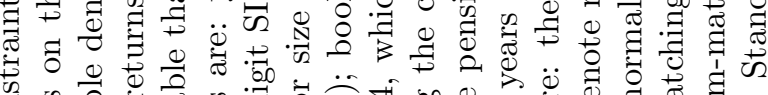

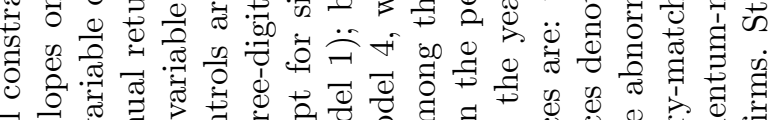

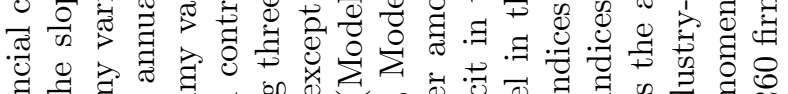

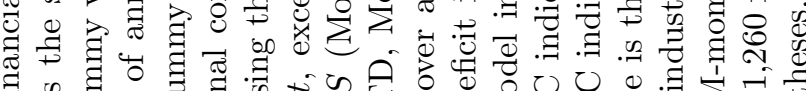

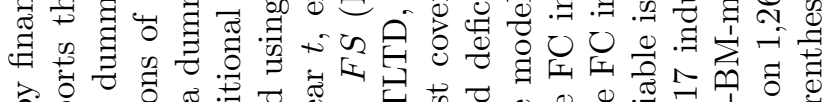
s.

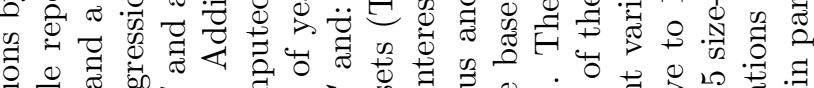

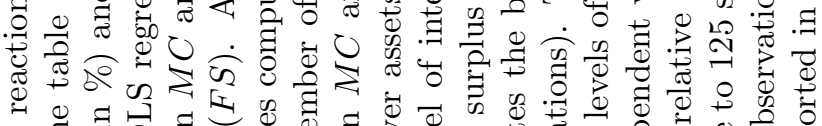
o $\begin{aligned} & 0 \\ & 0\end{aligned}$

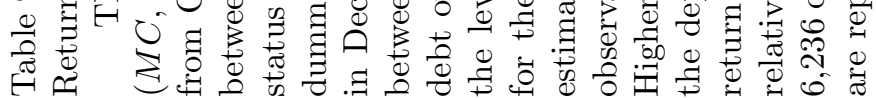

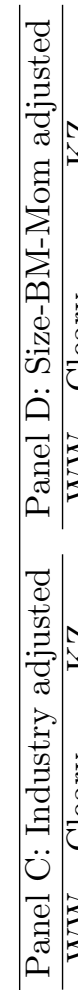

焉

क人ष

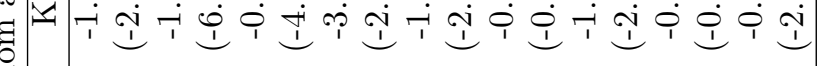

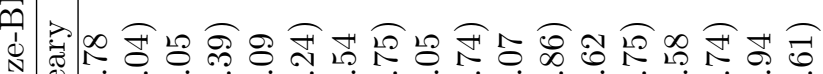

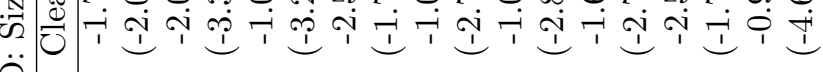

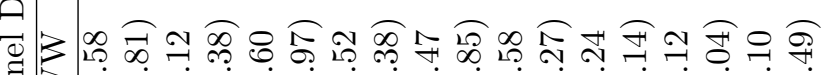

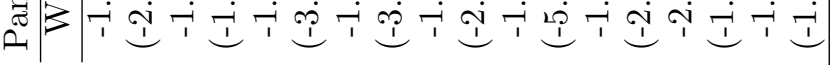

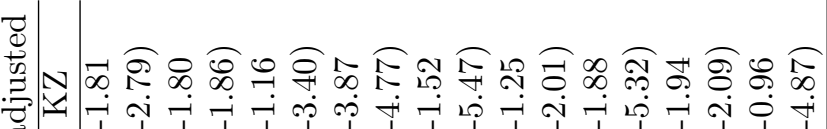
券 可

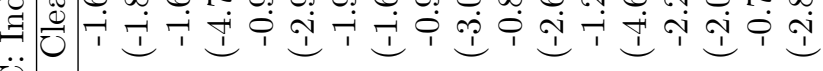
ব)

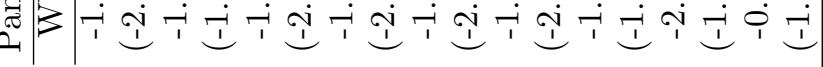

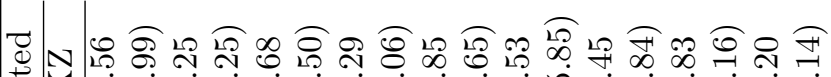
幽 寄

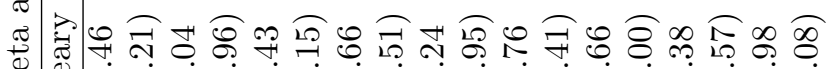
صी $\ddot{\oplus}$

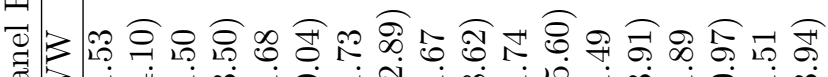

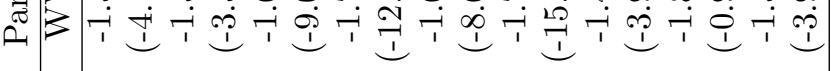

N 言

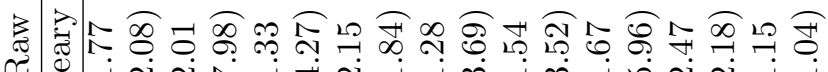

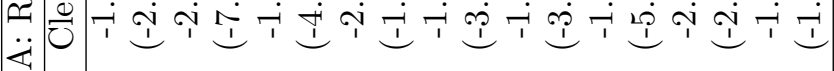

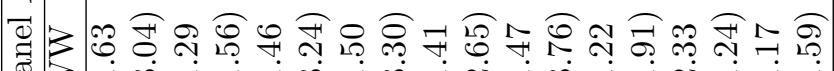
बा|

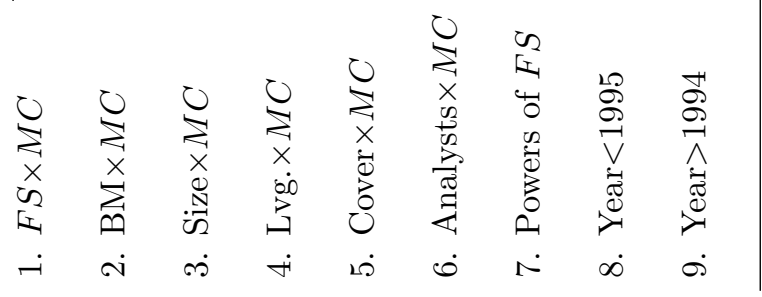




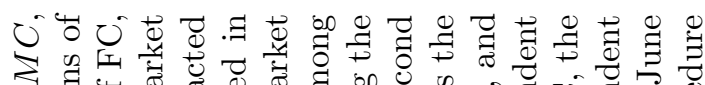

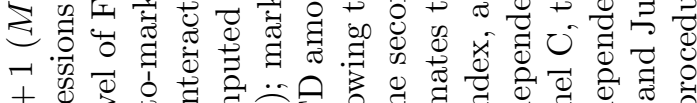
+

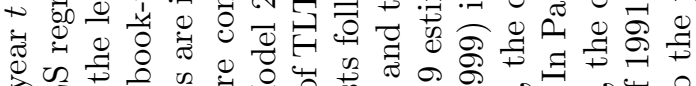

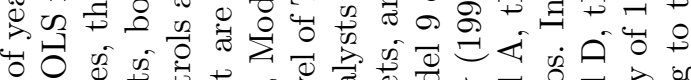
等

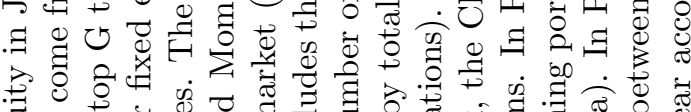

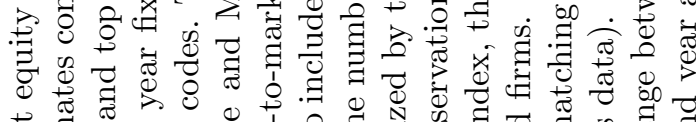
홀

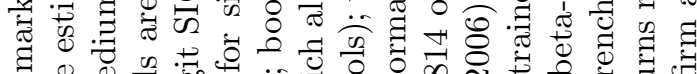
日

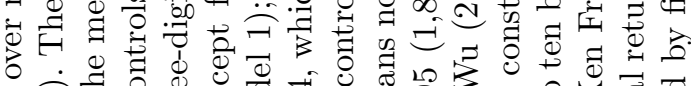

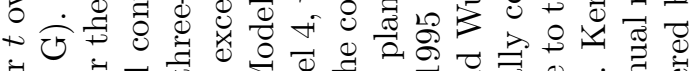

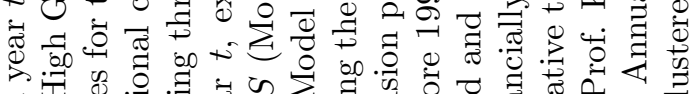

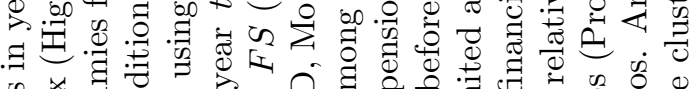

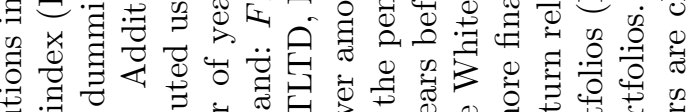

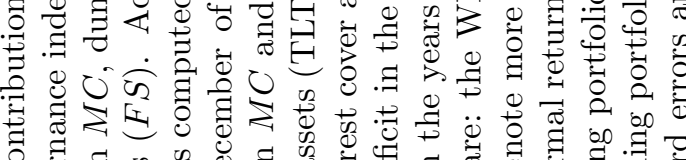

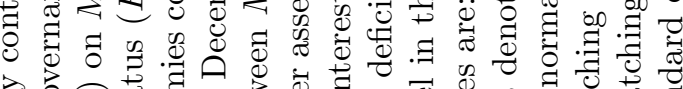

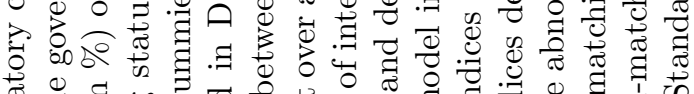

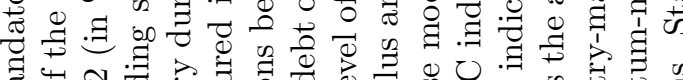

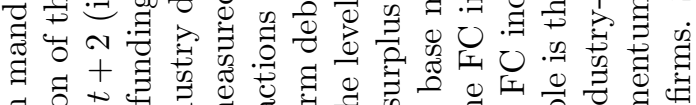

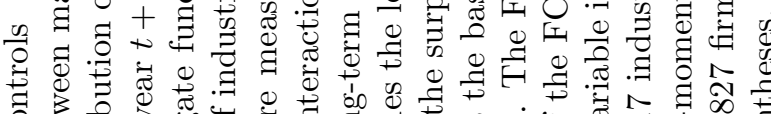
3

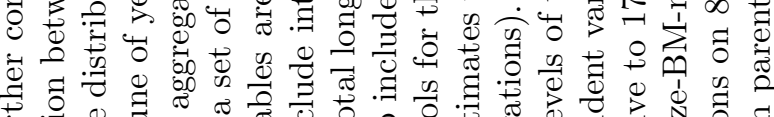

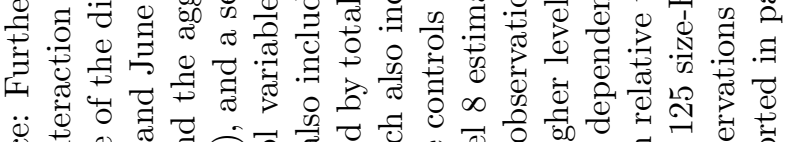

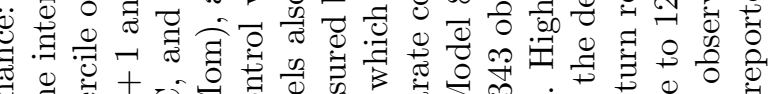

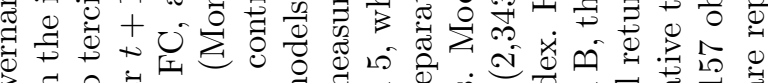

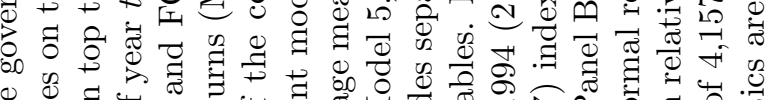

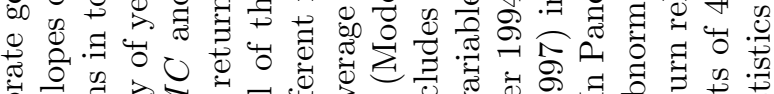

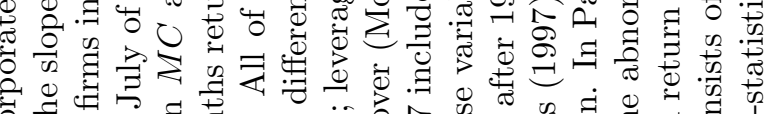

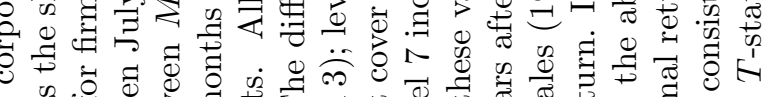

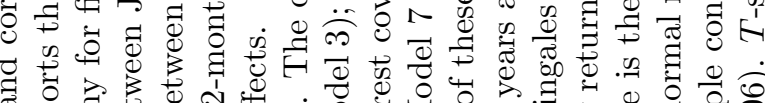

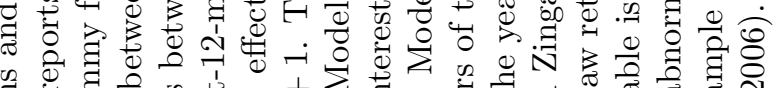

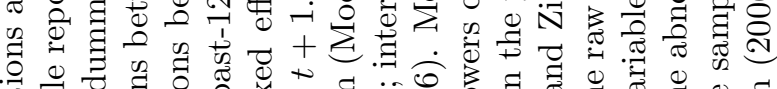

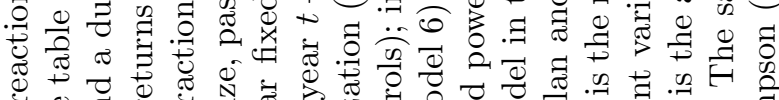

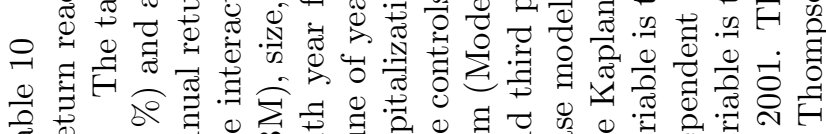

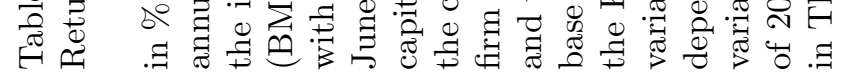

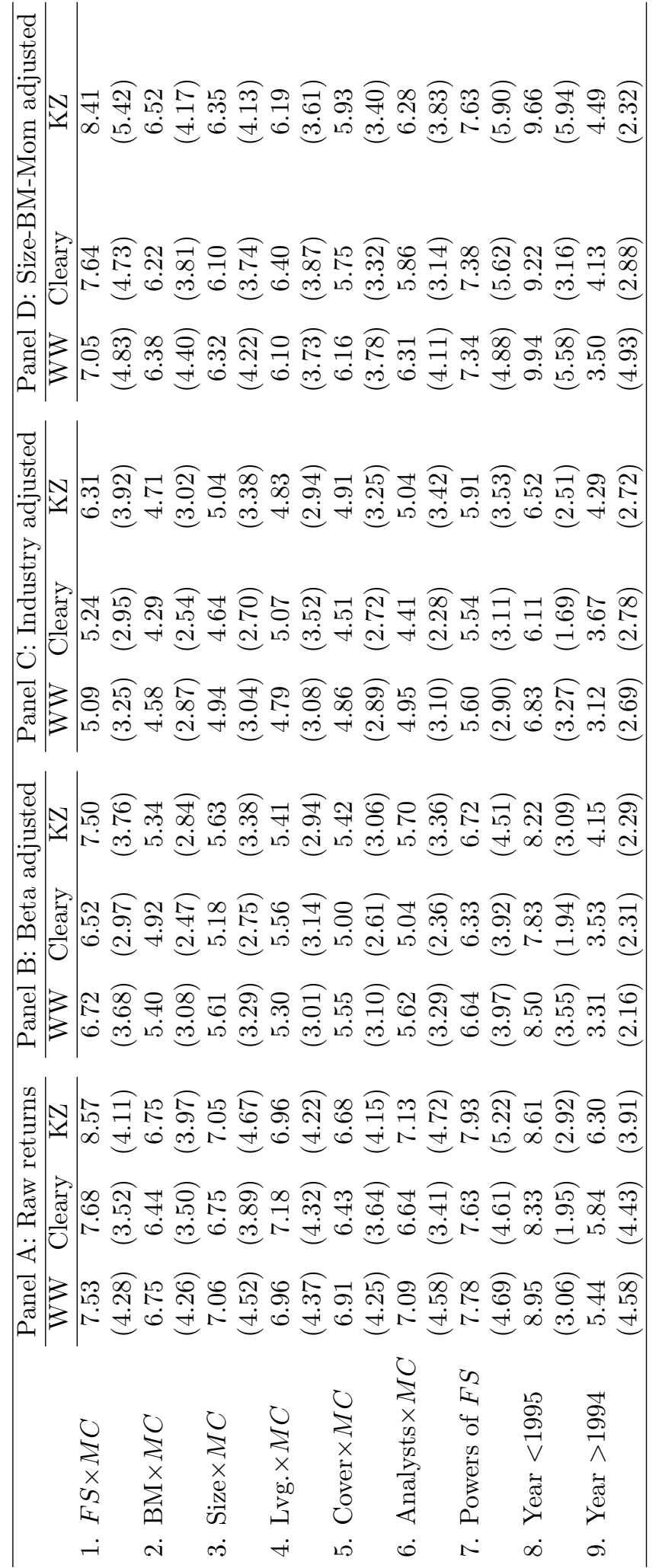




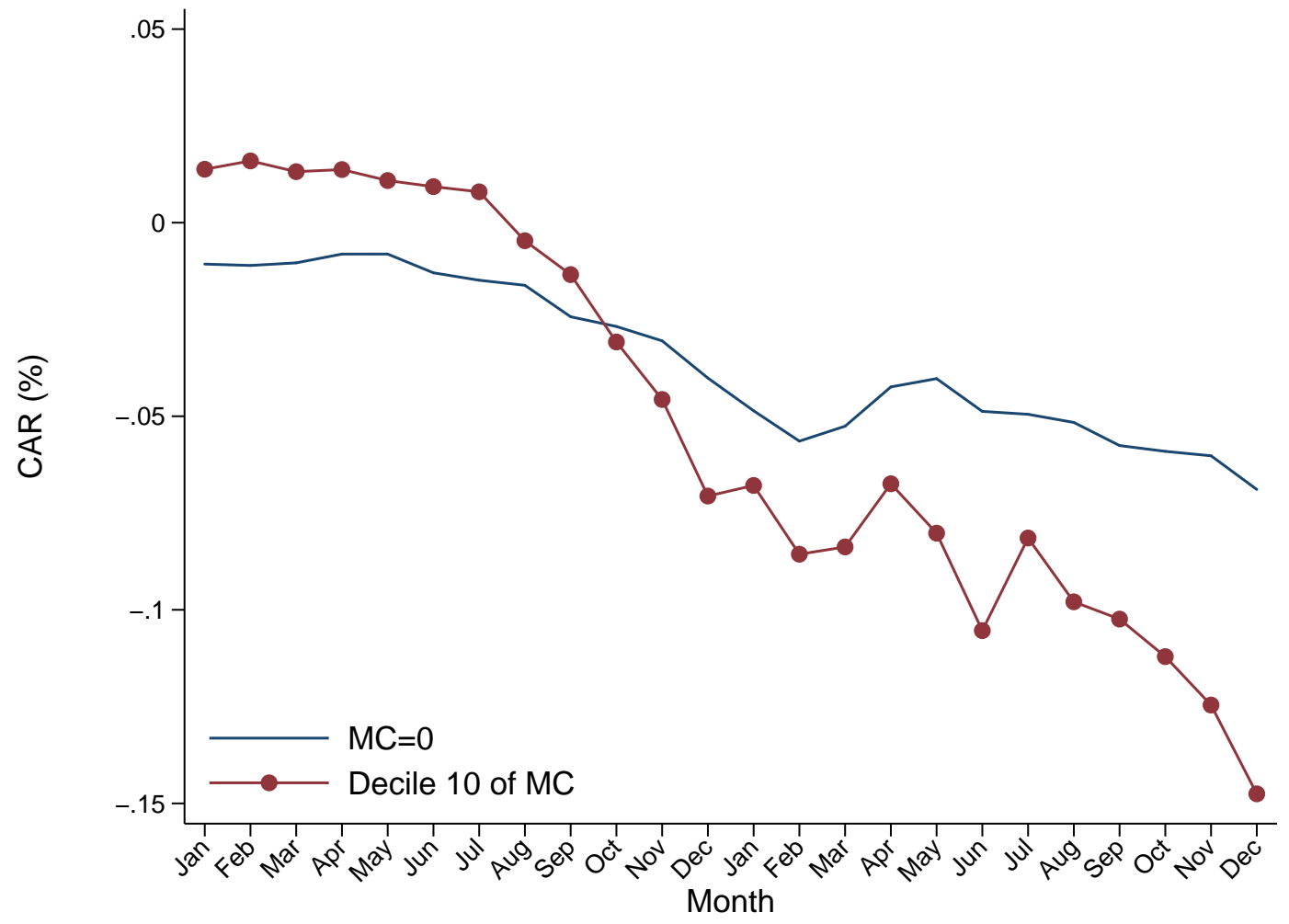

Fig. 1. Cumulative abnormal returns for top-contributions payers and non-contribution payers. The graphs plots the cumulative abnormal returns (CAR) starting in January of year $t+1$ up to December of year $t+2$ for firms in different groups of the distribution of mandatory contributions $(M C)$ in year $t$ divided by total assets at the beginning of the year. Abnormal returns in percent are defined as the difference between the monthly stock return and the return on a size-BM-momentum matching portfolio. The circled line is the average CAR for the firms in the tenth decile of contributions conditioning on the observations with positive contributions. Across the sample years, there are 184 firm-year observations in this decile. The solid line is the average CAR for the firms with $M C=0$. This group is comprised of 4,427 firm-year observations. The sample of accounting data and company characteristics is limited to the period and firms for which mandatory contributions are available (1990-1999), as collected by Rauh (2006). 


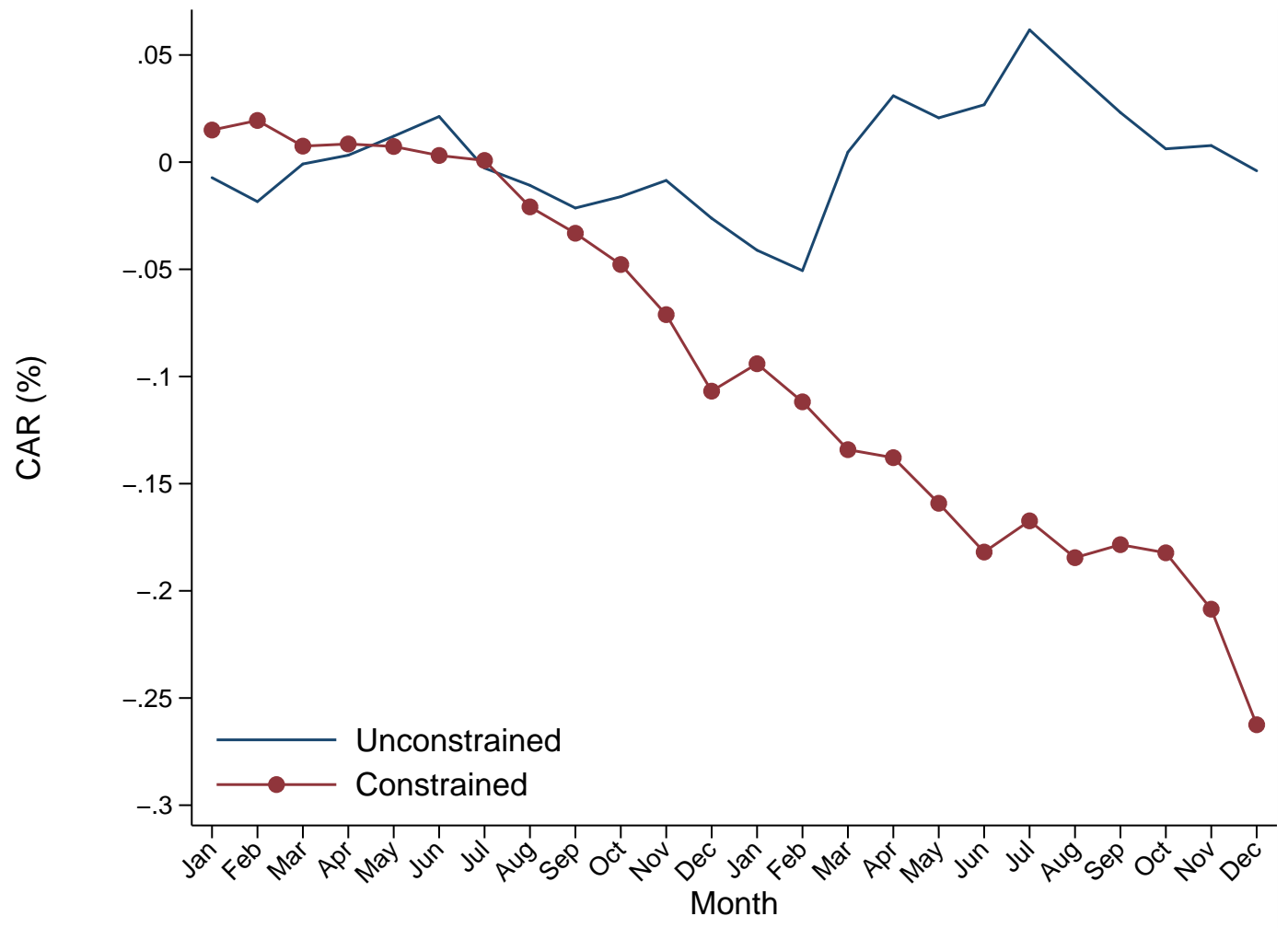

Fig. 2. Cumulative abnormal returns for constrained and unconstrained firms. The graphs plots the cumulative abnormal returns (CAR) starting in January of year $t+1$ up to December of year $t+2$ for firms in the top (constrained, circled line) and bottom (unconstrained, solid line) quartiles of the distribution of the Whited and $\mathrm{Wu}(2006)$ index, conditioning on the firms that each year experienced top-decile mandatory contributions to total assets. Abnormal returns in percent are defined as the difference between the monthly stock return and the return on a size-BM-momentum matching portfolio. The constrained group is comprised of 113 firm-year observations, while the unconstrained group is comprised of 22 observations. The sample of accounting data and company characteristics is limited to the period and firms for which mandatory contributions are available (1990-1999), as collected by Rauh (2006). 


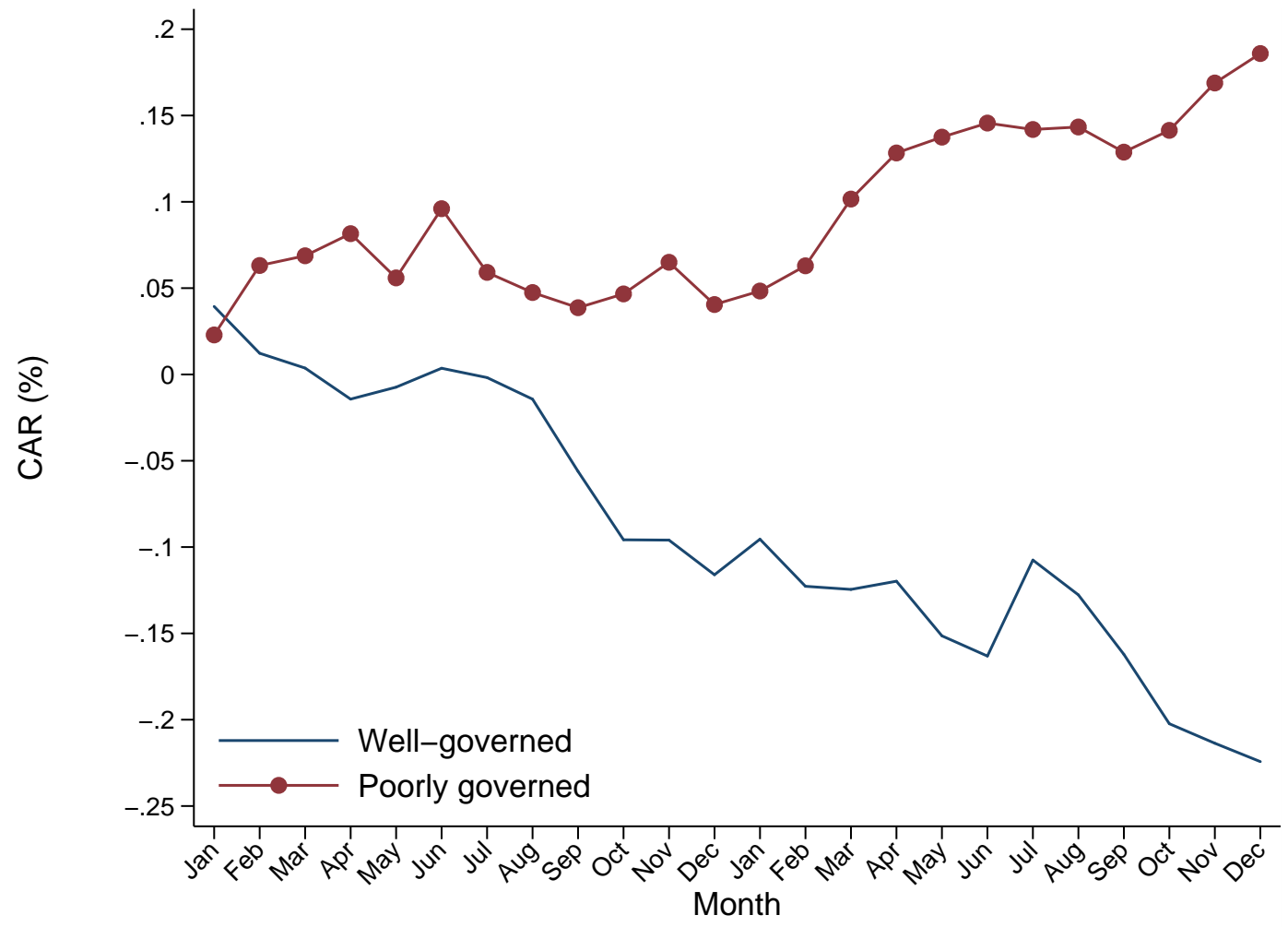

Fig. 3. Cumulative abnormal returns for well- and poorly governed firms. The graphs plots the cumulative abnormal returns (CAR) starting in January of year $t+1$ up to December of year $t+2$ for firms in the top (poorly governed, circled line) and bottom (well-governed, solid line) terciles of the distribution of the Gompers, Ishii, and Metrick (2003) index of corporate governance (G), conditioning on the firms that each year experienced top-decile mandatory contributions to total assets. Abnormal returns in percent are defined as the difference between the monthly stock return and the return on a size-BM-momentum matching portfolio. The well-governed group is comprised of 34 firm-year observations, while the poorly governed group is comprised of 20 observations. The sample of accounting data and company characteristics is limited to the period and firms for which mandatory contributions are available (1990-1999), as collected by Rauh (2006). 


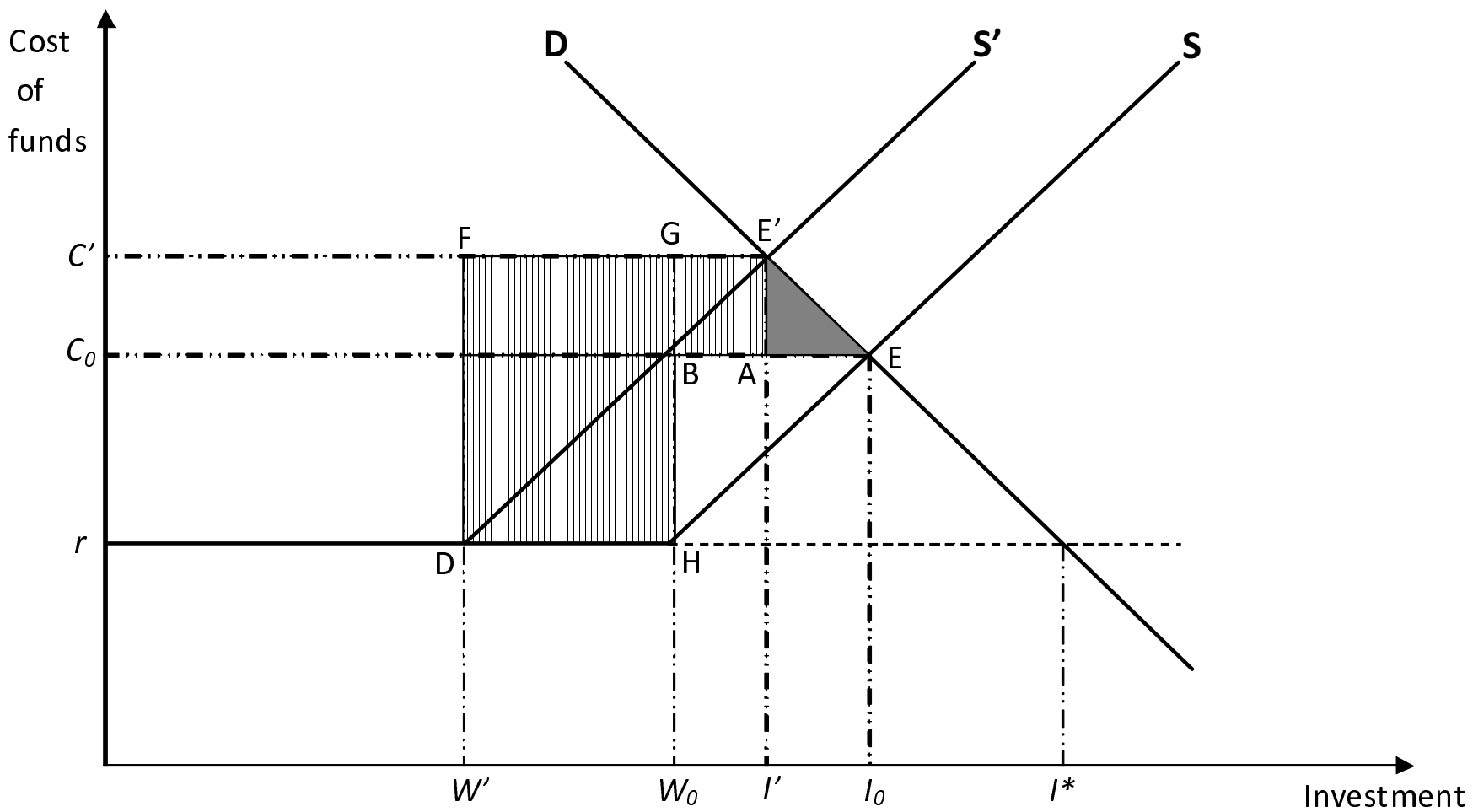

Fig. 4. Value impact of a drop in internal finance for financially constrained firms. The curve D depicts the downward-sloping investment demand, which is the inverse of the marginal profitability of investment, as a function of the cost of funds. The curve $\mathrm{S}$ represents the supply of capital, which is flat at the level of the firm's cost of capital $(r)$ up to the amount of available internal funds $\left(W_{0}\right)$. Beyond $W_{0}$, the supply curve slopes upwards to capture the increasing premium to external finance due to the costs of asymmetric information. Because of the financing frictions, the equilibrium level of investment $\left(I_{0}\right)$ is below the first-best level $\left(I^{*}\right)$ and the cost of funds $\left(C_{0}\right)$ is above the firm's frictionless cost of capital. As a result of a drop in internal resources from $W_{0}$ to $W^{\prime}$, the supply curves shifts to the left ( $\left.\mathrm{S}^{\prime}\right)$, and two components of the loss of surplus can be identified. First, the shaded triangle (AEE') captures the positive NPV of the forgone projects, as investment drops from $I_{0}$ to $I^{\prime}$. Second, the dashed area depicts the loss of value resulting from the fact that, due to the leftward shift of the supply curve, some of the surviving projects have to be funded at a higher cost $\left(C^{\prime}\right)$. This component, in turn, is made of two pieces: the additional cost of the projects that are externally funded before and after the shift (rectangle ABGE'); the additional cost of the projects that were internally funded before the shift and are now externally funded (rectangle DFGH). 

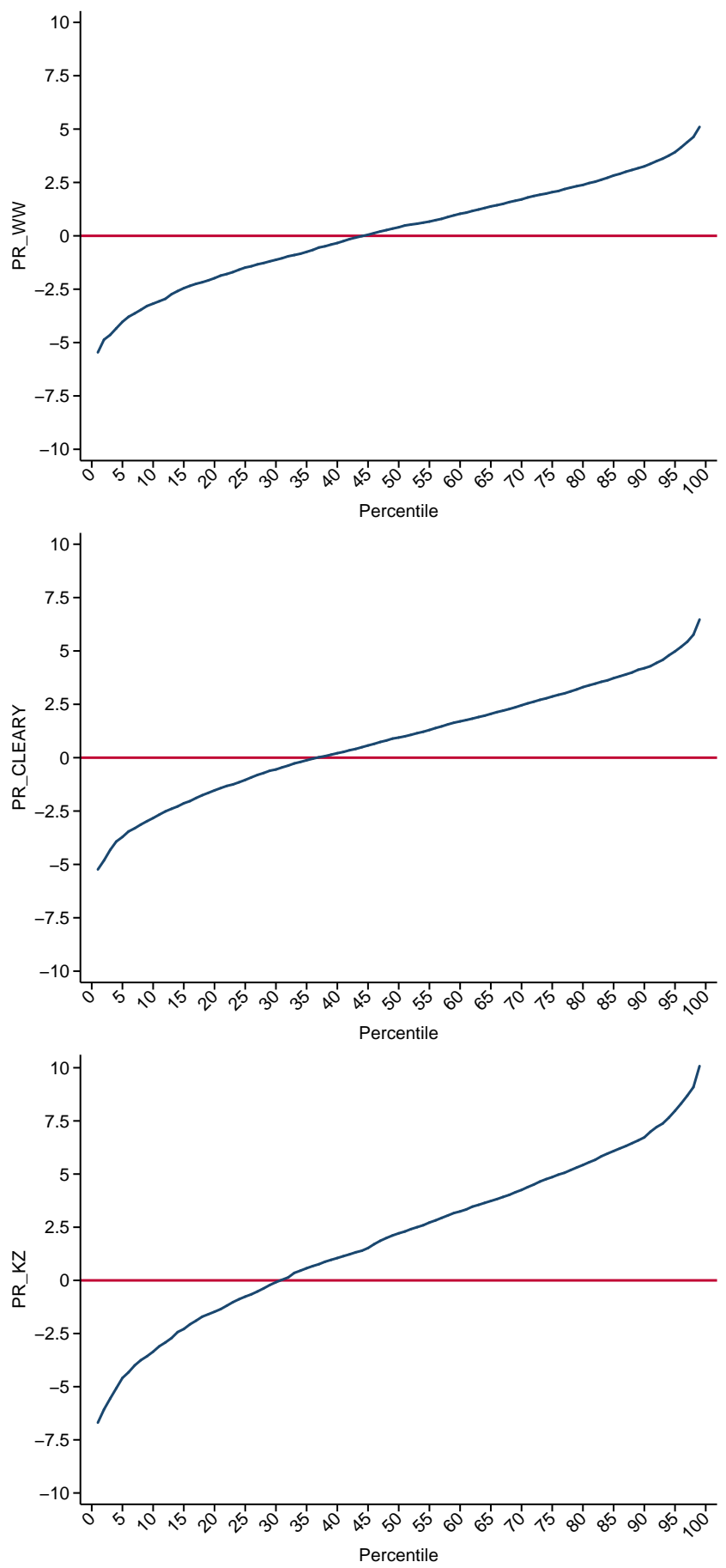

Fig. 5. Distribution of price reactions. The graphs plot the quantiles of the price reactions (PR, measured in $\$)$ to a one-dollar increase in mandatory contributions. The percentile number is on the horizontal axis and $\mathrm{PR}$ is on the vertical axis. Three versions of PR are constructed combining the Gompers, Ishii, and Metrick (2003) index of corporate governance $(\mathrm{G})$ and one of three indices of financial constraints (FC). PR for firm $i$ in year $t$ is: $P R_{i t}=\hat{\beta}_{1}+\hat{\beta}_{2} G_{i t}+\hat{\gamma}_{1} F C_{i t}$. The coefficients $\hat{\beta}_{1}, \hat{\beta}_{2}$, and $\hat{\gamma}_{1}$ refer to an estimate of Eq. 2 in the text. The financial constraints indices are: the Whited and Wu (2006) index (WW, top graph), the Cleary (1999) index (middle graph), and the Kaplan and Zingales (1997) index (KZ, bottom graph). Higher levels of the financial constraints indices denote more financially constrained firms. The sample consists of 4,157 observations on 827 firms between July of 1991 and June of 2001. 